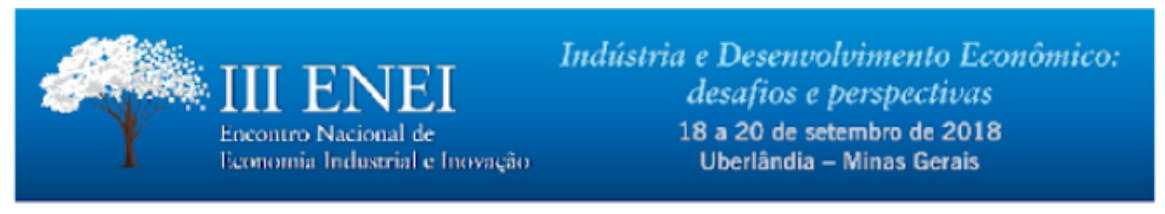

\title{
A Evolução da Interação Universidade-Empresa na Indústria do Rio Grande do Sul: 2008-2014
}

Rodrigo Morem da Costa*

Área 4.3 - Sistemas de inovação - nacional, regional, setorial, tecnológico

\begin{abstract}
$\underline{\text { Resumo }}$
Este estudo investiga a evolução da interação universidade-empresa na indústria do Rio Grande do Sul no período 2008-14, comparando esse processo com o observado em estados brasileiros e em nações industrializadas selecionadas. Os resultados encontrados mostram que houve uma evolução positiva das capacitações tecnológicas de empresas e de universidades gaúchas, com desempenho acima da média nacional, mas em patamar ainda inferior ao observado em nações desenvolvidas. Essa deficiência aparenta ser relativamente mais crítica para as empresas industriais do que para as universidades. Quanto a interação universidade-empresa no Rio Grande do Sul, mesmo com intensificação no período considerado, esta ainda é pouco frequente e coloca-se em nível inferior ao verificado em países avançados. Além disto, mesmo existindo elementos facilitadores para a interação universidade-empresa, outros fatores atuam como limitantes importantes, como as relativamente baixas capacitações tecnológicas das empresas industriais, a defasagem em alguns setores de alta e de média-alta intensidade tecnológica e a estrutura da indústria gaúcha, com predominância de setores industriais low-tech e pequena participação de empresas de portes médio e grande no total de empresas.
\end{abstract}

Palavras-chave: Interação universidade-empresa - inovação - indústria - Rio Grande do Sul - Brasil Classificação JEL: O31 - O43 - O54

\begin{abstract}
$\underline{\text { Abstract }}$
This study investigates the evolution of university-enterprise interaction in the industry of Rio Grande do Sul in the period 2008-14, with comparisons between this process and that one observed in selected Brazilian states and industrialized nations. The results points that has been occurring a positive evolution in the technological capabilities of the firms and universities of Rio Grande do Sul, with a performance above of the national average, but still at an inferior level than that observed in developed nations. This limitation appears to be relatively more critical to the industrial enterprises than to the universities. About the university-enterprise interaction in Rio Grande do Sul, even with intensification in the period considered, it is still infrequent and is at a lower level than that seen in advanced countries. In addition, even with the existence of elements that facilitate the universityenterprise interaction, other factors act as important constraints, such as the relatively still low technological capabilities of the industrial enterprises, the technological gap in some sectors of high and medium-high technology intensities and the industry structure, with a predominance of low-tech industries and small participation of enterprises of medium and large sizes as a share of the total.
\end{abstract}

Key words: university-enterprise interaction - innovation - industry - Rio Grande do Sul - Brazil JEL Classification: O31 - O43 - O54

\footnotetext{
* Doutor em Economia. Pesquisador da Fundação de Economia e Estatística - FEE/RS. Contato: rmorem@gmail.com.
} 


\section{Introduç̃̃o}

O objetivo deste estudo é analisar a evolução do padrão de interação universidade-empresa (U-E) na indústria do Rio Grande do Sul entre 2008 e 2014. É bem sabido que a interação entre universidades e empresas é um nexo fundamental em sistemas de inovação, cuja intensificação contribui para o surgimento e difusão de inovações, com efeitos positivos para o desenvolvimento econômico. O período 2008-2014 testemunhou aspectos positivos e negativos ao processo de inovação, em geral, e para a interação universidade-empresa em específico. Pelo lado positivo, no Brasil, as políticas industriais e de ciência e tecnologia no Brasil com foco no apoio à inovação nas empresas, que até então eram esparsas, ganharam centralidade como estratégia de desenvolvimento econômico a partir de 2003, sendo intensificadas até 2014 (MAZZUCATO; PENNA, 2016; RAPINI; CHIARINI; BITTENCOURT, 2017). A título de ilustração, algumas das políticas industriais e de ciência e tecnologia implantadas no Brasil pelo Governo Federal, com destaque no apoio à inovação após 2003 foram: Política Industrial, Tecnológica e de Comércio Exterior (PITCE), Fundo Nacional de Desenvolvimento Científico e Tecnológico, Lei da Inovação, Plano de Desenvolvimento Produtivo (PDP), Plano Brasil Maior. Similarmente, esse período também exibiu ações de fomento à inovação sendo intensificadas pelos governos de alguns Estados, incluindo-se aí o Rio Grande do Sul desde 1999, sobretudo, nos últimos anos. No Rio Grande do Sul, dentre as ações elaboradas e intensificadas pelo Governo do Estado de 1999 a 2014 e que tiveram relativo maior vulto, pode-se elencar as seguintes: Programa de Apoio aos Sistemas Locais de Produção (SLPs), Fundo Operação Empresa do Estado do Rio Grande do Sul (FUNDOPEM/RS); Programa Estadual de Fortalecimento das Cadeias e Arranjos Produtivos Locais (APLs); Programa Gaúcho de Apoio aos Parques Tecnológicos (PGTEC). Um maior detalhamento das ações pode ser encontrado em Antunes Júnior; Horn; Pellegrin; Vaz (2017). Também releva assinalar que entre 2008 e 2014, o Brasil passou por momentos conjunturais adversos, de incertezas e de crise econômica, afetando negativamente as decisões empresariais de investimento, inclusive em P\&D, em 2009 e 2013-2014 (IBGE, 2013; 2016). Nesse contexto, a pergunta de pesquisa que orientou o trabalho foi: como o padrão de interações U-E evoluiu no período 2008-2014, em relação a outros estados brasileiros e a nações industrializadas selecionadas? O estudo orienta-se pelo conceito de Sistemas de Inovação da teoria evolucionária, com ênfase nos relacionamentos existentes entre empresas e universidades. A metodologia empregada no estudo consiste de revisão da literatura e de análise de dados coletados em diferentes bases: Pesquisa de Inovação (PINTEC) do IBGE; diretório de grupos de pesquisa do CNPq; CAPES; INEP; Community Innovation Survey (CIS), dentre outras. Um conjunto de indicadores que refletem as capacitações tecnológicas de empresas industriais e de instituições de ensino superior e de pesquisa no Rio Grande do Sul foram definidos e analisados, bem como o padrão de interação universidade-empresa no Estado, de 2008 a 2014. O foco do estudo centra-se nas empresas das indústrias extrativas e de transformação e nas universidades. Afora esta Introdução, o texto está organizado em mais quatro seções abordando: (1) a revisão teórica; (2) a caracterização das capacitações tecnológicas das empresas industriais gaúchas; (3) capacitações em ensino e pesquisa das universidades Rio Grande do Sul; e (4) o padrão de interação universidade-empresa no Estado e sua evolução no período considerado. As considerações finais encerram o texto.

\section{1 - A Interacão Universidade-Empresa em Sistemas de Inovacão}

Sob a ótica da teoria econômica evolucionária é aceito que inovações, sobretudo as tecnológicas, desempenham um papel importante para a competitividade das empresas e para o desenvolvimento econômico. O conceito de Sistemas de Inovação (SI) ${ }^{1}$ estabelecido por esta teoria mostra-se útil ao entendimento do processo de desenvolvimento de novas tecnologias pelas empresas. Em uma abordagem ampla, um Sistema de Inovação pode ser definido como sendo o conjunto de firmas e organizações - inseridas em um contexto institucional ${ }^{2}$ - que estrutura e condiciona seus relacionamentos - que interagem com objetivo de explorar, buscar, produzir, transmitir e aprender novos conhecimentos científicos e tecnológicos, úteis ao processo de desenvolvimento e difusão de inovações (LUNDVALL, 2010, p.13). Em uma abordagem restrita, o SI engloba as organizações e instituições mais diretamente envolvidas nos processos de inovação (FREEMAN, 2010, p.173). Ambas as definições podem ser aplicadas a diferentes dimensões de SIs: nacional, regional, setorial e local.

\footnotetext{
${ }^{1}$ Doravante a sigla SI será utilizada como referência ao Sistema de Inovação.

${ }^{2} \mathrm{O}$ conceito de instituições aqui adotado tem o sentido de hábitos e rotinas de conduta, regras, contratos e organizações, que estruturam e condicionam as interações entre agentes econômicos, gerando ordem e estabilidade para a realização de ações coletivas (HODGSON, 1998, p. 170-172).
} 
A ideia básica de um SI é que os processos dos quais as inovações emergem são complexos, envolvendo o surgimento e a difusão de conhecimentos codificados e tácitos com possibilidades científicas e tecnológicas, sendo originários de múltiplas fontes. Isto requer a sua "tradução" em novos produtos ou processos produtivos e organizacionais, e o seu lançamento no mercado, envolvendo uma série de relações interativas e mecanismos de feedback (EDQUIST, 2011, p.1-2). Em outras palavras, as empresas não desenvolvem novos conhecimentos e projetam inovações apenas a partir de suas capacitações tecnológicas (humanas, financeiras, infraestrutura de laboratórios, etc.); de seus esforços formais de pesquisa e desenvolvimento (P\&D); de fontes informais de aprendizado; e de relações internas entre seus departamentos. $\mathrm{O}$ aprendizado de novos conhecimentos e o acesso a recursos para desenvolver ou implementar inovações também decorre da interação da empresa com o ambiente produtivo, científico, político e institucional no qual está inserida, assim como da relação que essas esferas mantêm com o resto do mundo (FREEMAN, 2008, p.80-81). Assim, as interações externas da firma envolvem competição, mas também comunicação e coordenação, permitindo o estabelecimento de relações de cooperação com outros atores para desenvolver inovações.

Embora os conhecimentos possam ser gerados por quaisquer dos agentes de um Sistema de Inovação, são as empresas que basicamente os materializam na forma de inovações em produtos, processos produtivos, rotinas organizacionais, etc., o que as torna centrais ao sistema. Além delas, três outros conjuntos de atores exercem papeis relevantes em um SI. O primeiro é formado pelas organizações de ensino e pesquisa - públicas e privadas - como universidades, institutos tecnológicos, laboratórios de metrologia, organizações de treinamento profissional, de consultoria, etc. O segundo consiste na ação do Estado, através de órgãos públicos e empresas estatais, enquanto formulador de política industrial e tecnológica; de fonte de recursos à inovação; de regulação da atividade econômica; e demandante, fomentador e empreendedor em inovações importantes à sociedade, mas que se mostrem onerosas e/ou arriscadas demais para serem desenvolvidas pelo setor privado (MAZZUCATO, 2014, p. 256-257). E o terceiro grupo consiste de organizações pertencentes ao sistema financeiro nacional, devido a que uma parcela do esforço tecnológico ocorrer através de financiamento, via crédito ou de outros mecanismos de alavancagem de recursos no mercado de capitais, como, por exemplo, o venture capital.

Quanto às universidades, sua atuação possui relevância particular para o desempenho do sistema de inovação, pois geram e transferem conhecimentos à sociedade por diferentes canais. Elas formam recursos humanos, dentre os quais se encontram pesquisadores em nível de mestrado e de doutorado; realizam pesquisas em ciência e tecnologia; prestam serviços tecnológicos; e servem como infraestrutura ${ }^{3}$ à realização de P\&D. Observe-se, também, que muitas empresas de base tecnológica (start-ups) são formadas pelo empreendedorismo de indivíduos ligados às pesquisas em universidades. Devido ao estabelecimento de vínculos com a produção científica internacional, as universidades constituem-se em um dos canais de entrada em um SI de conhecimentos gerados externamente. Em alguns casos, os conhecimentos gerados pelas pesquisas em universidades podem posteriormente dar origem a novas aplicações, inclusive radicais, ou solucionar eventuais gargalos à evolução tecnológica, gerando novas oportunidades de mercado às empresas (FREEMAN, 2010, p.187). Ademais, o acesso a pesquisadores e a laboratórios das universidades complementa as habilidades e recursos físicos, quando a empresa não dispõe de capacitações suficientes ${ }^{4}$ à solução de determinados problemas tecnológicos. Este ponto é particularmente relevante quando há descontinuidades na base de conhecimentos. Em especial, nos últimos anos a interação universidade-empresa vem aumentando de importância, devido à elevação da complexidade na base de conhecimento científico e a concomitante necessidade de pesquisa básica para seu avanço, sobretudo em setores high-techs. Com isso, vem se tornando muito caro para as empresas investirem na formação integral das capacitações tecnológicas requeridas ao desenvolvimento de muitas das novas tecnologias que estão emergindo (inteligência artificial, internet das coisas, novos materiais, etc.). Portanto, ao serem absorvidas ou acessadas pelas empresas, essas funções das universidades contribuem ao seu processo de formação de capacitações tecnológicas e de desenvolvimento de inovações, ampliando suas possibilidades competitivas (MOWERY; SAMPAT, 2005, p.211-212; SUZIGAN; ALBUQUERQUE; CARIO, 2011, p.9; SMITH, 2011, p.96-102).

Observe-se que a natureza das interações universidade-empresa é simbiótica, sendo um processo coevolutivo importante ao desenvolvimento de um SI (NELSON; ROSENBERG, 1999, p.46-57). Além das

\footnotetext{
${ }^{3}$ Além de equipamentos e laboratórios, a infraestrutura também pode compreender incubadoras e parques tecnológicos.

${ }^{4}$ Quando a firma não vislumbra um uso frequente para recursos humanos com determinada habilidade ou para um equipamento específico, a interação com universidades consiste em uma alternativa interessante à solução de gargalos no desenvolvimento de inovações, com menor custo em relação à alternativa de investir na formação interna destas capacitações.
} 
vantagens paras as empresas, as universidades se beneficiam de problemas tecnológicos trazidos pelas primeiras, que podem criar novos objetos de pesquisa para os cientistas. Inclusive, inovações radicais que criem novos mercados também podem originar novas áreas de conhecimento e disciplinas na academia. Nessa direção, demandas recorrentes por parte das empresas podem informar a atualização do currículo de disciplinas em cursos universitários. Além disto, avanços tecnológicos em diferentes dispositivos, como computadores, microscópios, telescópios, e outros dispositivos, têm contribuído ao avanço científico por melhorarem os processos de observação de fenômenos e de coleta e processamento de dados.

Alguns fatores atuam como facilitadores para a ocorrência da interação universidade-empresa, sobretudo, a proximidade cognitiva, física, social e institucional entre esses atores. A cognitiva favorece a transmissão de conceitos e de conhecimentos complementares entre esses atores. A proximidade física contribui à realização de interações face-a-face com frequência, inclusive, sendo importante à comunicação de conhecimentos tácitos. Além disto, a existência de capital social entre os partícipes e o contexto institucional compartilhado, contribuindo ao ordenamento desta relação, permitem intensificar a interação universidade-empresa. Nesse sentido, pesquisadores com mestrado e doutorado nas empresas, devido ao seu treinamento formal e à prática na realização de atividades internas de $\mathrm{P} \& \mathrm{D}$, constituem-se em facilitadores da interação com universidades. Isto porque, esses profissionais fazem a ligação entre os conhecimentos formais e os aplicados; estão familiarizados com o modus operandi (rotinas) da pesquisa universitária, que é distinto da empresarial; criam objetivos compartilhados entre essas organizações; e, usualmente, dispõem de uma rede de contatos nas universidades (capital social), advindo da passagem prévia quando de sua formação acadêmica, particularmente pós-graduada. Além disto, a organização da produção em aglomerações produtivas especializadas, sobretudo nos chamados Arranjos Produtivos Locais, possibilita um fluxo mais intenso e recorrente de informações entre empresas e universidades. Por outro lado, convém observar que, quando a firma se depara com um problema de elevada complexidade, particularmente em inovações radicais, o elemento orientador da busca pela interação com a universidade constitui-se na excelência em pesquisa acadêmica na área de interesse (COSTA; RUFFONI; PUFFAL, 2011, p. 215-220; GARCIA; ARAUJO; MASCARINI; SANTOS, 2014, p. 108-109).

Mesmo existindo benefícios mútuos na interação universidade-empresa, nem sempre esses agentes se mostram interessados em buscar tal relacionamento. Assim, cabe indicar alguns dos aspectos mais recorrentes, computados pela literatura, que dificultam sua ocorrência (CAMPOS, 2010, p.384; BUCHARTH, 2011, p.106108; SCHEFFER; RUFFONI; PUFAL, 2015, p.110-113). Para as empresas, os elementos restritivos internos à cooperação com universidades dizem respeito, entre outros, ao estágio do ciclo de vida tecnológico do produto ${ }^{5}$; ao elevado grau de incerteza sobre os resultados de projetos conjuntos; e à amplitude de suas capacitações tecnológicas, quais sejam, nível de qualificação e de conhecimento dos pesquisadores; orçamento para financiar projetos conjuntos de P\&D; e infraestrutura à realização dessas atividades internamente. Os limitantes externos podem ser atribuídos a fatores como: distanciamento da pesquisa universitária em relação à sua aplicação prática e imediata; dificuldades na regulação relacionada à transferência de tecnologia das universidades para as empresas; complexidade e velocidade da burocracia universitária; e duração dos projetos conjuntos. Quanto às universidades, dentre os fatores internos que inibem a interação com empresas podem ser elencados: perda de liberdade de pesquisa; contratos voltados para o curto prazo; elevada burocracia; e dificuldades organizacionais e institucionais no uso de recursos. Dentre os fatores externos, os principais seriam a diferença no nível de conhecimento em relação aos interlocutores da firma (distância cognitiva); o conflito entre o direito de propriedade da patente (empresa) e de divulgação dos resultados da pesquisa (universidade); e dificuldades para obtenção de financiamento para a realização de projetos conjuntos.

\section{2-Caracterizacão das Capacitacões Tecnológicas das Empresas Industriais do Rio Grande do Sul}

Como pré-requisito à análise da interação das empresas industriais ${ }^{6}$ com universidades no Rio Grande do Sul, convém caracterizar ambos os conjuntos de atores deste SI. Em 2014, na indústria gaúcha as unidades produtivas com mais de cinco pessoas ocupadas eram em número de 21.868, possuíam 735.046 empregados, e geraram valor da transformação industrial (VTI) de R $\$ 78,7$ bilhões (Tabela 1). Esses números respondem por

\footnotetext{
${ }^{5}$ Produtos em fases iniciais de seu ciclo de vida tecnológico - radicalmente novos - em geral possuem maior probabilidade de incorrerem em descontinuidades na base de conhecimentos, podendo motivar a interação universidade-empresa.

${ }^{6}$ Nesse texto, o termo "indústria" será empregado para se referir às atividades das indústrias extrativas e de transformação.
} 
8,8\% do emprego e por 7,2\% do VTI das indústrias extrativas e de transformação do País, o que colocou o Estado como o quarto no ranking industrial nacional por critério de tamanho do $\mathrm{VTI}^{7}$. Em 2014, os oito principais setores industriais do Estado responderam juntos por cerca de 70\% do VTI e por 66,5\% do emprego (Tabela 1). Quando agregadas as atividades industriais por intensidade tecnológica ${ }^{8}$, somando-se os valores do VTI, se observa que a estrutura do Rio Grande do Sul era formada por 33,7\% de setores high-tech e 66,3\% de low-tech, enquanto que para a média do Brasil elas representaram respectivamente $27,6 \%$ e $72,4 \%$.

Em termos da estrutura por porte dos estabelecimentos da indústria do Rio Grande do Sul em 2014, 82,9\% eram de microempresas, $13,6 \%$ pequeno, $2,8 \%$ médio e $0,6 \%$ grande, os quais foram responsáveis, respectivamente, por $20,4 \% ; 23,8 \% ; 27,6 \%$ e $28,2 \%$ do total do emprego ${ }^{9}$. Esses dados revelam que as médias e grandes empresas industriais, que em tese teriam melhores condições para sustentar atividades contínuas de P\&D, representavam 3,4\% dos estabelecimentos e 55,8\% do emprego da indústria gaúcha. Entre os setores industriais, os com maior participação de estabelecimentos de médio e de grande porte no Estado foram: automotivo (10,9\%); fabricação de produtos químicos $(6,6 \%)$; fabricação de produtos de borracha e de material plástico $(6,1 \%)$; e fabricação de produtos alimentícios $(5 \%)$.

Tabela 1: Dados selecionados das unidades industriais do Rio Grande do Sul com 5 ou mais pessoas ocupadas - 2014

\begin{tabular}{|c|c|c|c|c|c|c|}
\hline \multirow{2}{*}{$\begin{array}{c}\text { Classificação Nacional de Atividades } \\
\text { Econômicas (CNAE 2.0) }\end{array}$} & \multirow{2}{*}{$\begin{array}{c}\text { Intensidade } \\
\text { Tecnológica (OCDE) }\end{array}$} & \multirow{2}{*}{$\begin{array}{c}\text { Unidades } \\
\text { locais } \\
\mathrm{N}^{\circ}\end{array}$} & \multicolumn{2}{|c|}{ Pessoal ocupado } & \multicolumn{2}{|c|}{ Valor da transformação industria } \\
\hline & & & $\mathrm{N}^{\mathrm{o}}$ & $\%$ & R\$ Bilhões & $\%$ \\
\hline Total & $\mathbf{N} / \mathbf{A}$ & 21.868 & 735.046 & 100,0 & $\mathbf{7 8 , 7}$ & $\mathbf{1 0 0 , 0}$ \\
\hline - (B) Indústrias extrativas & Baixa & 372 & 6.146 & 0,8 & 0,6 & 0,8 \\
\hline - (C) Indústrias de transformação & $\mathrm{N} / \mathrm{A}$ & 21.496 & 728.900 & 99,2 & 78,1 & 99,2 \\
\hline -- (10) Produtos alimentícios & Baixa & 2.758 & 131.599 & 17,9 & 13,6 & 17,3 \\
\hline -- (28) Máquinas e equipamentos & Média-alta & 1.533 & 70.610 & 9,6 & 8,6 & 11,0 \\
\hline -- (29) Automotivo & Média-alta & 512 & 51.164 & 7,0 & 8,0 & 10,1 \\
\hline -- (20) Produtos químicos & Média-alta & 530 & 17.175 & 2,3 & 6,3 & 8,1 \\
\hline -- (15) Couros e calçados & Baixa & 2.802 & 119.607 & 16,3 & 5,3 & 6,8 \\
\hline -- (25) Produtos de metal & Média-baixa & 2.824 & 62.560 & 8,5 & 5,3 & 6,7 \\
\hline -- (19) Coque, deriv. petróleo e biocombustív. & Média-baixa & 17 & 1.541 & 0,2 & 4,9 & 6,2 \\
\hline -- (22) Produtos de borracha e plástico & Média-baixa & 1.014 & 34.881 & 4,7 & 3,4 & 4,3 \\
\hline -- Outros & $\mathrm{N} / \mathrm{A}$ & 9.506 & 239.763 & 32,6 & 22,7 & 28,9 \\
\hline
\end{tabular}

Fonte: IBGE (2017b); OCDE (2011).

No que tange à sua evolução no Rio Grande do Sul de 2008 a 2014, a indústria vem apresentando baixo dinamismo, em média, com perda de participação na estrutura do valor adicionado bruto (VAB) e do emprego da economia estadual ${ }^{10}$. No período, o VAB da economia gaúcha cresceu $39,2 \%$ e o emprego total elevou-se em $23,3 \%$, enquanto que para a sua indústria este aumento foi de respectivamente $18,5 \%$ e de $10,8 \%$. Desse modo, sua participação na economia do Estado declinou de 20\% no VAB e de 25,6\% no emprego em 2008 para, respectivamente, $17 \%$ e $23 \%$ em 2014 . Deve-se considerar que além de dificuldades competitivas, essa queda de importância da indústria na economia estadual também está relacionada ao efeito da conjuntura adversa, devido aos efeitos da crise financeira mundial em 2008-11 e da desaceleração da economia brasileira no período 201314 , que a afetaram mais do que as das demais atividades (IBGE, 2013; 2016). Contudo, dado que as quedas de participação no VAB e no emprego foram praticamente contínuas no período, pode-se perceber esse processo como tendo um forte componente de desindustrialização e de mudança estrutural.

Quanto à evolução das capacitações tecnológicas da indústria do Rio Grande do Sul, convém lançar mão da análise de alguns indicadores, enquanto aproximações, para seu potencial para desenvolver ou para assimilar

\footnotetext{
${ }^{7}$ Cálculos com base em dados da PIA-Empresa (IBGE, 2017b).

${ }^{8}$ Essa classificação segue a taxonomia de intensidade de esforço tecnológico da OCDE (2011). As atividades high-techs consistem nas classificadas com intensidade tecnológica "alta" e "média-alta" e as low-techs como "média-baixa" e "baixa".

${ }^{9}$ Cálculos com base no número de estabelecimentos e de empregos da Relação Anual de Informações Sociais (RAIS) (BRASIL, 2017) e delimitação de porte de estabelecimentos industriais por número de empregados, de acordo com a metodologia do Serviço Brasileiro de Apoio às Micro e Pequenas Empresas (SEBRAE, 2017), assim classificados: microempresa, entre 1 e 19 empregados; pequena, entre 20 e 99 ; média, entre 100 e 499 ; e grande, com 500 e mais empregados.

${ }^{10}$ Cálculos realizados com base em dados da FEE (2016) e RAIS (BRASIL, 2017), deflacionando os valores para preços constantes de 2014 pelo IGPDI/FGV (IPEA, 2017).
} 
inovações. De 2008 a 2014 observa-se que, em geral, embora o gasto total em atividades de inovação ${ }^{11}$ tenha se reduzido no Estado e no País, ainda assim, os dispêndios em P\&D interno vieram aumentando, com taxas de crescimento $^{12}$ de $66,1 \%$ para o Rio Grande do Sul e de 22,9\% para a média brasileira. Esse movimento se observa em todas as Unidades da Federação analisadas (Tabela 2). Inclusive, isto se reflete em maior intensidade de esforço tecnológico interno, mensurado como a fração destes dispêndios em relação à receita líquida de vendas das empresas $^{13}$, que na indústria do Rio Grande do Sul foi de 0,39\% em 2008, de 0,60 em 2011 e de 0,65 em 2014, enquanto que na brasileira foi respectivamente de $0,62 \% ; 0,71 \%$ e de $0,67 \%$. Ademais, no processo de desenvolvimento de inovações nos triênios 2006-08, 2009-11 e 2012-14, a proporção de empresas que atribuíram relevância alta ou média para as atividades internas de P\&D elevou-se de $11,2 \%$ para $17,8 \%$ e finalmente $21,1 \%$ no Estado, enquanto que essa evolução no Brasil saiu de $11,5 \%$ para $15,9 \%$ e para $15,2 \%{ }^{14}$. Isto indica que o esforço tecnológico interno voltado ao desenvolvimento próprio de inovações vem ganhando importância na indústria, o que é relevante por resultar em maior absorção de conhecimentos, diferenciação de produtos e formação de infraestrutura à $\mathrm{P} \& \mathrm{D}$, ampliando as possibilidades futuras das empresas. Trata-se, portanto, de uma mudança qualitativa importante na estrutura dos dispêndios em atividades de inovação, que vem se processando no País nos últimos anos, sendo relativamente mais intensa no Rio Grande do Sul. Entretanto, note-se que a fração dos dispêndios em P\&D interno relativo ao total das atividades de inovação no Estado encontrava-se abaixo da média nacional, ainda que o hiato em relação a 2008 tenha se reduzido.

Tabela 2 - Dispêndios realizados em atividades de inovação por empresas industriais inovadoras no Brasil: 2008-14 Valores em R $\$$ bilhões a preços de 2014

\begin{tabular}{|c|c|c|c|c|c|c|c|c|c|}
\hline \multirow{2}{*}{ Unidades da Federação } & \multicolumn{3}{|c|}{ Atividades de Inovação } & \multicolumn{3}{|c|}{ P\&D Interno } & \multicolumn{3}{|c|}{ P\&D Interno/AI - (\%) } \\
\hline & 2008 & 2011 & 2014 & 2008 & 2011 & 2014 & 2008 & 2011 & 2014 \\
\hline Brasil & 60,4 & 60,3 & 57,6 & 14,8 & 18,0 & 18,2 & 24,5 & 29,8 & 31,5 \\
\hline São Paulo & 30,3 & 27,0 & 27,4 & 8,0 & 7,7 & 8,8 & 26,3 & 28,7 & 32,2 \\
\hline Rio de Janeiro & 5,6 & 7,3 & 6,4 & 2,7 & 5,0 & 3,7 & 47,7 & 68,3 & 57,8 \\
\hline Minas Gerais & 8,0 & 7,6 & 4,5 & 1,7 & 1,6 & 1,2 & 20,8 & 20,6 & 26,3 \\
\hline Rio Grande do Sul & 3,8 & 3,4 & 3,5 & 0,6 & 0,9 & 1,1 & 17,1 & 27,6 & 30,3 \\
\hline Paraná & 2,9 & 2,9 & 3,2 & 0,5 & 0,7 & 0,8 & 18,2 & 25,1 & 25,0 \\
\hline Santa Catarina & 2,1 & 3,5 & 2,7 & 0,4 & 0,9 & 0,9 & 16,9 & 24,5 & 33,4 \\
\hline Outros & 7,8 & 8,5 & 9,9 & 1,0 & 1,1 & 1,7 & 12,5 & 13,2 & 17,0 \\
\hline
\end{tabular}

Fonte: IBGE (2010, 2013 e 2016).

Notas: Empresas das indústrias extrativas e de transformação, com 10 ou mais empregados, que implementaram produto e/ou processo novo ou substancialmente aprimorado. Valores deflacionados para preços de 2014 pelo IGP-DI/FGV (IPEA, 2017).

Cabe considerar que o desempenho apresentado nos gastos em atividades de inovação, destacando-se nesse conjunto o P\&D interno, por empresas industriais do Rio Grande do Sul e dos demais Estados brasileiros, ainda as posiciona em 2014 em um nível intermediário de esforço tecnológico em relação a nações industrializadas. Isto pode ser observado na proporção do esforço tecnológico interno das empresas industriais, computados em termos de gasto em P\&D interno em relação ao PIB (Gráfico 1).

Gráfico 1: Gastos em P\&D interno de empresas industriais em relação ao PIB de Estados e de Países Selecionados em 2014 - (\%)

\begin{tabular}{|c|c|c|c|c|c|c|c|c|c|c|c|c|c|c|c|c|c|c|c|c|c|c|c|c|}
\hline $\begin{array}{l}3,50 \\
3,00 \\
2,50 \\
2,00 \\
1,50 \\
1,00 \\
0,50 \\
0,00\end{array}$ & $\begin{array}{r}0,22 \\
\end{array}$ & $\begin{array}{r}0,23 \\
\end{array}$ & $\begin{array}{r}0,23 \\
\end{array}$ & $\begin{array}{r}0,25 \\
\end{array}$ & $\begin{array}{r}0,30 \\
\\
\end{array}$ & $\begin{array}{r}0,30 \\
\end{array}$ & $\begin{array}{r}0,31 \\
\end{array}$ & $\begin{array}{r}0,35 \\
\\
\end{array}$ & $\begin{array}{r}0,37 \\
\\
\end{array}$ & $\begin{array}{c}0,42 \\
-\end{array}$ & $\begin{array}{c}0,44 \\
-\end{array}$ & 0,47 & 0,54 & 0,55 & 0,62 & 0,67 & 0,88 & 1,07 & 1,37 & 1,42 & 1,52 & 1,69 & 2,29 & 2,98 \\
\hline & $\underset{\mathscr{E}}{\stackrel{\Xi}{\Xi}}$ & 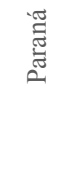 & 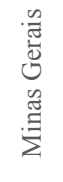 & 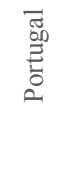 & 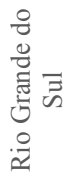 & 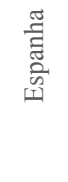 & $\begin{array}{l}\overline{\mathscr{n}} \\
\bar{\pi} \\
\vec{n}\end{array}$ & $\begin{array}{l}\text { ర్ } \\
0 \\
0 \\
0 \\
Z\end{array}$ & 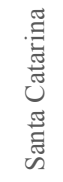 & 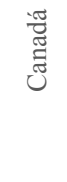 & 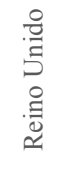 & 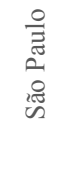 & 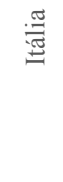 & 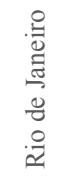 & $\begin{array}{l}\text { త্ } \\
\dot{\Xi} \\
\dot{0} \\
\dot{0} \\
\simeq\end{array}$ & $\begin{array}{l}\frac{\pi}{\tilde{Z}} \\
\frac{\pi}{0} \\
\text { I }\end{array}$ & 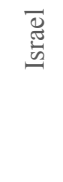 & 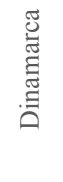 & 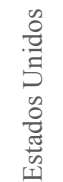 & 节 & 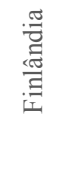 & 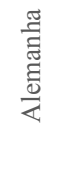 & 荵 & $\begin{array}{l}\overline{3} \\
\text { W } \\
0 \\
0 \\
\frac{\pi}{0} \\
0 \\
0 \\
0\end{array}$ \\
\hline
\end{tabular}

Fonte: IBGE (2016; 2017c); OCDE (2017a e 2017b).

Nota: Empresas das indústrias extrativas e de transformação com 10 ou mais empregados que implementaram inovações.

\footnotetext{
${ }^{11}$ As atividades de inovação compreendem: Atividades internas de P\&D; Aquisição externa de P\&D; Aquisição de outros conhecimentos externos; Aquisição de software; Aquisição de máquinas e equipamentos; Treinamento; Introdução das inovações tecnológicas no mercado; e Projeto industrial e outras preparações técnicas.

${ }^{12}$ Cálculos com base nos dados da Tabela 2.

${ }^{13}$ Cálculos com base em dados das PINTECs 2008, 2011 e 2014 (IBGE, 2010, 2013 e 2016).

${ }^{14}$ Cálculos com base em dados das PINTECs 2008, 2011 e 2014 (IBGE, 2010, 2013 e 2016).
} 
Em relação aos outros dois indicadores de capacitações tecnológicas das empresas, ou seja, infraestrutura e recursos humanos, agrupados como proxy para os principais tipos de insumos no desenvolvimento de inovações, verifica-se que de 2008 para 2014 houve uma nítida tendência de aumento em algumas das variáveis selecionadas. No que concerne à infraestrutura, uma aproximação para este tipo de capacitação consiste em avaliar o número daquelas empresas que realizaram atividades internas de $\mathrm{P} \& \mathrm{D}$, sobretudo de caráter contínuo, pois isso exige alguma dotação, pelo menos mínima, de laboratórios e de equipamentos. Ademais, a continuidade na execução de P\&D permite maior domínio das rotinas associadas a essa atividade, gerando maior eficiência em sua realização. No Rio Grande do Sul e no Brasil, de um modo geral, dentre as empresas industriais que implementaram inovações de produto e/ou de processo produtivo entre 2008 e 2014, aumentou o número daquelas que inovaram realizando dispêndios em atividades internas contínuas de $\mathrm{P} \& \mathrm{D}$, ganhando participação. No Rio Grande do Sul, essa proporção passa de 9,2\% em 2008 para 18\% em 2014, apresentando elevação com continuidade. Na média nacional, a mesma proporção variou de 9,9\% em 2008 para 12,4\% em 2014, embora com oscilação em seu crescimento. Isto também reflete uma maior intensidade do processo de ganho de capacitações tecnológicas na indústria no Rio Grande do Sul em relação a outros Estados brasileiros no período. Inclusive, em 2014 o Estado mostrou a maior participação (18\%) de empresas com dispêndios contínuos em P\&D interno sobre o total que inovou na indústria (Tabela 3). Aponte-se, também, que o número absoluto de empresas industriais gaúchas que inovaram com investimento contínuo em P\&D foi de 305 em 2008 e de 728 em 2014, perfazendo um crescimento de 138,4\% (IBGE, 2010; 2013; 2016). Inclusive, o Rio Grande do Sul possui o segundo maior contingente da indústria nacional de empresas que inovaram realizando P\&D contínuo. Portanto, o ganho em capacitações se deu tanto de modo absoluto quanto relativo. Contudo, convém salientar, ainda é pequena a fração de empresas industriais que realizam atividades internas de P\&D com continuidade para inovar, tanto no Estado quanto no País.

Tabela 3: Indicadores selecionados de capacitações tecnológicas em infraestrutura e em recursos humanos das empresas industriais brasileiras que implementaram inovações: $2008-2014$

\begin{tabular}{|c|c|c|c|c|c|c|c|c|c|c|c|c|}
\hline \multirow[t]{2}{*}{ Unidade da Federação } & \multicolumn{6}{|c|}{$\begin{array}{c}\text { Infraestrutura } \\
\text { Empresas com dispêndios em atividades de inovação }\end{array}$} & \multicolumn{6}{|c|}{$\begin{array}{c}\text { Recursos Humanos } \\
\text { Pessoal ocupado em atividades de P\&D }\end{array}$} \\
\hline & 2008 & 2011 & 2014 & 2008 & 2011 & 2014 & 2008 & 2011 & 2014 & 2008 & 2011 & 2014 \\
\hline Brasil & 30.645 & 32.616 & 34.583 & 9,9 & 13,2 & 12,4 & 48.096 & 71.351 & 105.267 & 9,1 & 8,0 & 7,4 \\
\hline São Paulo & 10.063 & 10.477 & 10.108 & 13,6 & 15,9 & 17,0 & 24.433 & 32.909 & 50.104 & 8,1 & 8,2 & 7,7 \\
\hline Santa Catarina & 2.710 & 2.732 & 3.671 & 10,5 & 12,1 & 7,7 & 3.562 & 5.128 & 8.749 & 5,8 & 7,3 & 3,9 \\
\hline Minas Gerais & 4.238 & 4.582 & 3.846 & 5,6 & 9,8 & 9,1 & 3.952 & 7.942 & 9.336 & 12,4 & 7,6 & 8,4 \\
\hline Paraná & 2.890 & 2.863 & 3.331 & 7,7 & 14,1 & 10,8 & 2.839 & 4.718 & 7.810 & 6,1 & 7,0 & 3,1 \\
\hline Rio de Janeiro & 1.127 & 1.403 & 1.302 & 18,1 & 21,2 & 15,0 & 3.939 & 5.949 & 6.615 & 23,7 & 15,7 & 16,1 \\
\hline Outras & 6.291 & 6.727 & 8.285 & 6,3 & 7,8 & 7,9 & 4.644 & 6.497 & 10.762 & 6,6 & 7,5 & 8,2 \\
\hline
\end{tabular}

Fonte: IBGE $(2010,2013,2016)$.

Nota: Foram consideradas apenas as empresas das indústrias extrativas e de transformação com 10 ou mais empregados que implementaram produto e/ou processo tecnologicamente novo ou substancialmente aprimorado.

Quanto aos recursos humanos exercendo atividades de P\&D nas empresas industriais do Rio Grande do Sul que implementaram inovações, este contingente mostrou evolução positiva no período 2008-14, com crescimento de $151,5 \%$. Na média nacional, esta taxa de crescimento foi de $118,9 \%$. Uma forma mais acurada de identificar as capacitações tecnológicas em recursos humanos consiste em avaliar a parcela de pós-graduados, em que praticamente sua totalidade está ocupada como pesquisadores. De um lado, normalmente estes profissionais são detentores de um maior nível de conhecimento e de qualificação para a realização de atividades de P\&D. De outro lado, como destacado anteriormente, os pesquisadores pós-graduados são importantes ao estabelecimento de relações com as universidades e demais instituições de pesquisa. Ao longo do período, o Rio Grande do Sul mostrou o segundo maior contingente brasileiro de recursos humanos em P\&D. Contudo, na indústria do Rio Grande do Sul, a fração do pessoal pós-graduado oscilou em torno de uma baixa participação, de 3,9\% a 6,5\%, do total empregado em atividades de $\mathrm{P} \& D$. Note-se que esta porção ainda esteve abaixo da média industrial brasileira no período, assim como não recuperou em 2014 o patamar de 2008. No absoluto, o número de pós-graduados em empresas industriais gaúchas se ampliou em 94,9\%, de 309 em 2008 para 602 em 2014. No agregado da indústria do Brasil, a proporção de pós-graduados apresentou tendência de decréscimo, de 9,1\% em 2008 para 7,4\% em 
2014 (Tabela 3). Quanto ao número destes pesquisadores no Brasil, este cresceu 76,6\%, de 4.398 em 2008 para 7.768 em 2014. Observe-se, novamente, que houve ganho relativo de capacitações tecnológicas na dimensão de recursos humanos, sendo mais intensa no Rio Grande do Sul do que na média nacional. Cabe indicar que o ganho de capacitação foi mais pelo aumento absoluto do pessoal em P\&D, mas com perda no relativo, dado ter diminuída a proporção de pós-graduados.

Em conjunto, embora tenha ocorrido um ganho de capacitação tecnológica na indústria do Rio Grande do Sul e do Brasil, nos três principais fatores relevantes ao desenvolvimento ou absorção de inovações investimentos, recursos humanos e infraestrutura à $\mathrm{P} \& \mathrm{D}$ - estas ainda podem ser consideradas baixas, dada a pequena representação nos respectivos totais.

\section{3 - Caracterizaç̃o e Capacitaç̃es das Universidades do Rio Grande do Sul}

No universo das instituições de ensino superior e de pesquisa existentes em 2014, o Rio Grande do Sul contava com uma infraestrutura formada por um total de 120 organizações, divididas em 19 universidades, cinco centros universitários, 93 faculdades e três Institutos Federais (IFs)/Centros Federais de Educação Tecnológica (CEFETs), (INEP, 2017a). No Estado havia ainda três parques tecnológicos em operação até 2014: Tecnopuc (PUCRS), Tecnosinos (UNISINOS) e Valetec (FEEVALE) (BERNARDINI et al., 2014). Nesse universo de instituições, em 2014 o Rio Grande do Sul contava com 2.292 cursos presenciais em nível de graduação e 356 de Pós-Graduação (INEP, 2017a; CAPES, 2017b).

Tabela 4: Índice Geral de Cursos (IGC) das Universidades e Institutos Federais do Brasil em 2014 - Top 7 Instituições Brasileiras e Ranking das do Rio Grande do Sul

\begin{tabular}{|c|c|c|c|c|c|}
\hline Nome da IES & $\begin{array}{l}\text { Conceito } \\
\text { médio da } \\
\text { Graduação }\end{array}$ & $\begin{array}{l}\text { Conceito } \\
\text { Médio do } \\
\text { Mestrado }\end{array}$ & $\begin{array}{l}\text { Conceito } \\
\text { Médio do } \\
\text { doutorado }\end{array}$ & $\begin{array}{c}\text { IGC } \\
\text { (Contínuo) }\end{array}$ & $\begin{array}{c}\text { Ranking } \\
\text { Geral }\end{array}$ \\
\hline Universidade Estadual de Campinas & 3,0 & 4,9 & 4,9 & 4,4 & $1^{\circ}$ \\
\hline Universidade Federal do Rio Grande do Sul & 3,4 & 4,9 & 5,0 & 4,3 & $2^{\circ}$ \\
\hline Universidade Federal da Integração Latino-Americana & 4,3 & 4,0 & 0,0 & 4,2 & $3^{\circ}$ \\
\hline Universidade Federal de Minas Gerais & 3,4 & 4,9 & 4,9 & 4,2 & $4^{\circ}$ \\
\hline Universidade Federal de São Paulo & 3,0 & 4,6 & 4,8 & 4,2 & $5^{\circ}$ \\
\hline Universidade Federal de Santa Catarina & 3,3 & 4,8 & 4,9 & 4,1 & $6^{\circ}$ \\
\hline Universidade Federal do Rio de Janeiro & 3,1 & 4,8 & 4,9 & 4,1 & $7^{\mathrm{o}}$ \\
\hline Fund. Univ. Federal de Ciências da Saúde de Porto Alegre & 3,7 & 4,3 & 4,4 & 3,9 & $14^{\circ}$ \\
\hline Universidade Federal de Santa Maria & 3,3 & 4,5 & 4,8 & 3,8 & $16^{\mathrm{o}}$ \\
\hline Universidade do Vale do Rio dos Sinos & 3,3 & 4,7 & 4,9 & 3,6 & $27^{\circ}$ \\
\hline Pontifícia Universidade Católica do Rio Grande do Sul & 3,0 & 4,9 & 4,9 & 3,5 & $31^{\circ}$ \\
\hline Universidade Federal de Pelotas & 2,9 & 4,4 & 4,8 & 3,4 & $42^{\circ}$ \\
\hline Fundação Universidade Federal do Pampa & 3,2 & 4,0 & 4,5 & 3,3 & $51^{\circ}$ \\
\hline Universidade Federal do Rio Grande & 2,7 & 4,4 & 4,8 & 3,2 & $55^{\circ}$ \\
\hline Universidade Estadual do Rio Grande do Sul & 3,2 & 0,0 & 0,0 & 3,2 & $56^{\circ}$ \\
\hline Universidade FEEVALE & 3,1 & 4,5 & 4,9 & 3,2 & $60^{\circ}$ \\
\hline Univ. Reg. do Noroeste do Estado do Rio Grande do Sul & 3,0 & 4,4 & 4,5 & 3,1 & $63^{\circ}$ \\
\hline Inst. Fed. de Educação, Ciência e Tecnologia Farroupilha & 3,1 & 0,0 & 0,0 & 3,1 & $64^{\circ}$ \\
\hline Inst. Fed. de Educação, Ciência e Tec. do Rio G. do Sul & 3,1 & 0,0 & 0,0 & 3,1 & $66^{\circ}$ \\
\hline Universidade Católica de Pelotas & 2,7 & 4,7 & 4,9 & 3,1 & $69^{\circ}$ \\
\hline Universidade de Santa Cruz do Sul & 2,9 & 4,4 & 5,0 & 3,0 & $74^{\circ}$ \\
\hline Inst. Fed. de Educação, Ciência e Tec. Sul-Rio-Grandense & 3,0 & 4,0 & 0,0 & 3,0 & $75^{\circ}$ \\
\hline Universidade de Caxias do Sul & 2,8 & 4,4 & 4,8 & 2,9 & $97^{\circ}$ \\
\hline Universidade de Cruz Alta & 2,8 & 4,0 & 0,0 & 2,8 & $114^{\circ}$ \\
\hline Universidade de Passo Fundo & 2,7 & 4,3 & 4,5 & 2,8 & $123^{\circ}$ \\
\hline Univ. Reg. Integ. do Alto Médio Uruguai e das Missões & 2,7 & 4,2 & 5,0 & 2,7 & $126^{\circ}$ \\
\hline Universidade Luterana do Brasil & 2,4 & 4,4 & 4,5 & 2,5 & $173^{\circ}$ \\
\hline Universidade da Região da Campanha & 2,4 & 0,0 & 0,0 & 2,4 & $182^{\circ}$ \\
\hline
\end{tabular}

Fonte: INEP (2017b).

Nota: A sigla CPC corresponde ao Conceito Preliminar de Cursos. O IGC é construído com base em uma média ponderada das notas dos cursos de graduação e pós-graduação de cada instituição, compreendendo as avaliações do CPC e da CAPES, sendo uma média trienal dos resultados no ano de cálculo e nos dois anos anteriores. 
$\mathrm{Na}$ avaliação de cursos superiores de 2014, expressa pelo $\mathrm{IGC}^{15}$, as universidades e institutos federais do Rio Grande do Sul apresentaram um bom desempenho, em média, quando comparadas às suas congêneres de outros Estados (Tabela 4). No IGC, a Universidade Federal do Rio Grande do Sul (UFRGS) figurou como a principal instituição do Estado, além de aparecer na segunda posição nacional dentre as 228 avaliadas, com destaque nos conceitos obtidos na média dos cursos de mestrado e de doutorado, respectivamente, na primeira e na oitava posição. Outras organizações estaduais que obtiveram algum destaque no ranking nacional do IGC foram a UFCSPA como a $14^{\text {a }}$ no geral e a segunda melhor colocada em cursos de graduação; a UNISINOS como segunda melhor universidade privada e a $18^{\mathrm{a}}$ entre os mestrados; a PUCRS como quinta colocada entre as privadas e a segunda entre os mestrados. Ademais, no ranking do IGC figuram seis instituições do Estado dentre as 50 melhores do País.

Em relação aos 356 cursos de pós-graduação do Rio Grande do Sul em 2014, 54 (15,2\%) estavam no rol daqueles que se pode considerar como de "excelência" acadêmica, ou seja, que atingiram conceitos 7 ou 6 na avaliação da CAPES ${ }^{16}$. Por este critério, o Estado figurou na terceira colocação nacional, sendo precedido por São Paulo (20,2\%) e Rio de Janeiro (15,6\%) (Tabela 5). Note-se que, embora o Rio Grande do Sul detenha 9,5\% dos cursos de pós-graduação do Brasil, as universidades gaúchas respondem por 13\% dos cursos de "excelência" acadêmica. Entre as universidades do Rio Grande do Sul, a UFRGS se destaca com 32 cursos de pós-graduação considerados como sendo de excelência acadêmica, sendo sucedida pela PUC-RS com 11.

Tabela 5: Total de Cursos de Pós-Graduação e Cursos de Excelência Acadêmica no Brasil em 2014

\begin{tabular}{|c|c|c|c|c|c|}
\hline \multirow[b]{2}{*}{ Unidade da Federação } & \multicolumn{2}{|c|}{ Total de Cursos (TC) } & \multicolumn{3}{|c|}{ Cursos de Excelência Acadêmica (EA) } \\
\hline & $\mathrm{TC}$ & $\mathrm{TC}-\%$ & EA & EA - \% & $\mathrm{EA} / \mathrm{TC}-\%$ \\
\hline Brasil & 3.748 & 100,0 & 415 & 100,0 & 11,1 \\
\hline São Paulo & 840 & 22,4 & 170 & 41,0 & 20,2 \\
\hline Rio de Janeiro & 435 & 11,6 & 68 & 16,4 & 15,6 \\
\hline Rio Grande do Sul & 356 & 9,5 & 54 & 13,0 & 15,2 \\
\hline Minas Gerais & 378 & 10,1 & 53 & 12,8 & 14,0 \\
\hline Santa Catarina & 141 & 3,8 & 18 & 4,3 & 12,8 \\
\hline
\end{tabular}

Fonte: GEOCAPES (CAPES, 2017b).

Observação: O número de cursos de pós-graduação é o somatório dos cursos de (a) mestrado profissional, de (b) mestrado, de (c) doutorado e de (d) mestrado/doutorado. Considera-se como "excelência acadêmica" o somatório do número de cursos com conceitos 6 e 7 na avaliação da CAPES.

Observe-se que de 2008 a 2014, as instituições de ensino superior no Rio Grande do Sul e no Brasil vieram em um processo de ganho de capacitações, de intensidade similar, o que se expressa na evolução da proporção de professores com doutorado sobre o efetivo total (Gráfico 2). Inclusive, é de observar que este indicador para o Estado foi superior ao do País ao longo do período, o que aponta para maiores capacitações para desempenhar suas atividades na média das instituições de ensino superior estaduais. Em 2014, essas ficaram em segundo lugar no Brasil, com $44,5 \%$ de seus professores com doutorado, abaixo apenas das do Rio de Janeiro com $46,7 \%{ }^{17}$. Esse diagnóstico também foi constatado para outros indicadores representativos das capacitações das instituições de ensino superior gaúchas no período 2009-12 por Bernardini et al. (2014, p.15-29). Ademais o mesmo estudo identificou um desempenho similar em indicadores de resultado, como na proporção de jovens matriculados em cursos de graduação e de pós-graduação e de produção científica por autor.

\footnotetext{
${ }^{15} \mathrm{O}$ Índice Geral de Cursos (IGC), calculado pelo Instituto Nacional de Estudos e Pesquisas Educacionais Anísio Teixeira (INEP), pode ser considerado uma aproximação que reflete a qualidade média dos cursos universitários.

${ }^{16} \mathrm{Na}$ avaliação de cursos de pós-graduação da Coordenação de Aperfeiçoamento de Pessoal de Nível Superior (CAPES) são atribuídos conceitos, que variam de 1 (mínimo) a 7 (máximo), para diferentes critérios: (a) titulação e experiência em orientação do corpo docente, (b) produção intelectual, (c) infraestrutura de ensino e pesquisa, (d) interação com grupos de pesquisa no exterior e (e) realização de programas de iniciação científica com alunos de graduação (CAPES, 2017a).

${ }^{17}$ Cálculos com base em dados do INEP (2017a).
} 
Gráfico 2: Total de professores e percentual com doutorado em instituições de ensino superior no Rio Grande do Sul e no Brasil

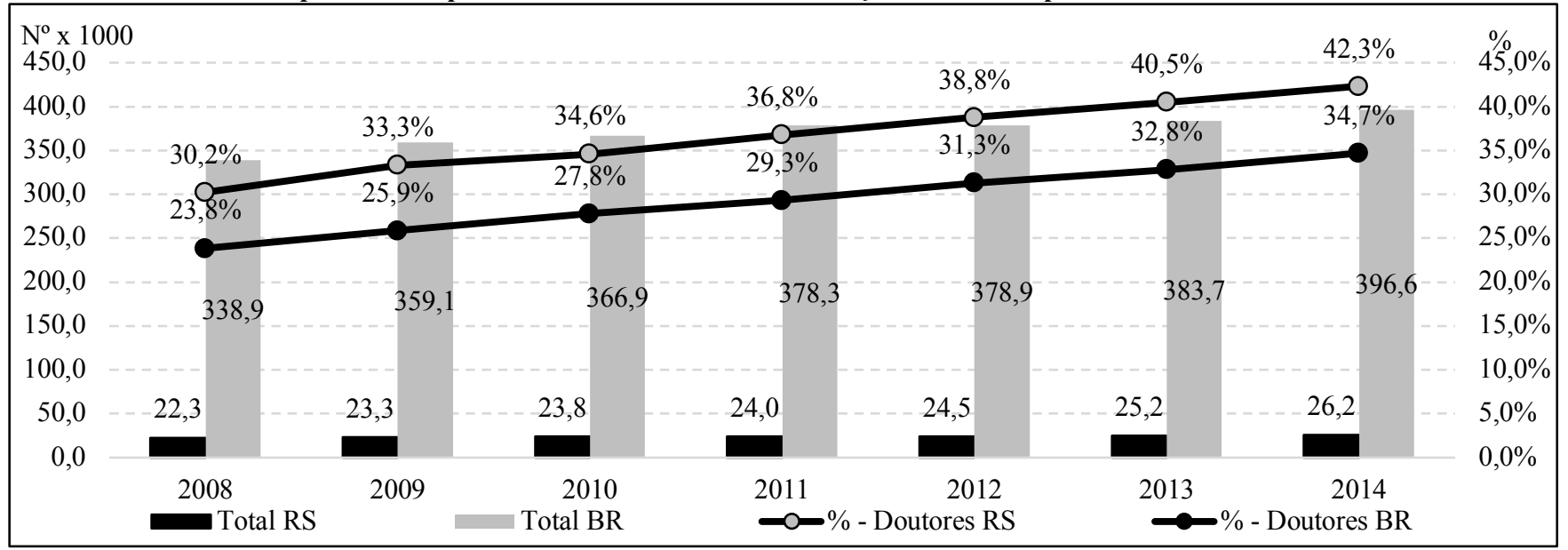

Fonte: INEP (2017a).

Em uma análise ampla das informações sobre as instituições de ensino superior do Rio Grande do Sul, quando comparadas nacionalmente, pode-se concluir que estas organizações apresentam um desempenho considerado bom e, em alguns casos, excelente, em indicadores de capacitações em geração de novos conhecimentos científicos e tecnológicos, de formação de pessoal qualificado em pesquisa, e de infraestrutura para a realização de atividades de $\mathrm{P} \& D$. Entretanto, na comparação internacional, apenas sete universidades brasileiras (1,4\%) conseguiram figurar entre as 500 melhores no ranking internacional de qualidade QS em 2015: USP-SP $\left(143^{\mathrm{a}}\right.$ ), UNICAMP-SP (195 $)$, UFRJ-RJ (323 $)$, UFRGS-RS (entre $451^{\mathrm{a}}$ e $460^{\mathrm{a}}$ ), UNESP-SP (entre $481^{\mathrm{a}}$ e $490^{\mathrm{a}}$ ), UNB-DF e UNIFESP-SP (entre $491^{\mathrm{a}}$ e $500^{\mathrm{a}}$ ) (TOPUNIVERSITIES, 2017). Chama a atenção que São Paulo abriga quatro das sete universidades nacionais no Top 500.

No cômputo total, o quadro que se forma no período 2008-14 é o de que o Rio Grande do Sul possui um dos Sistemas de Inovações mais desenvolvidos, para o padrão nacional, na dimensão de suas empresas industriais e universidades. O Estado figurou como um dos cinco mais industrializados, bem como com firmas com capacitações tecnológicas acima da média nacional em alguns indicadores. Dentre as instituições de ensino superior do Brasil, as gaúchas se destacam com um dos maiores potenciais para a formação de recursos humanos qualificados e para a geração de conhecimentos científicos e tecnológicos. Inclusive, observou-se um processo positivo de evolução das capacitações de ambos os atores nos últimos anos. Isto pode ser atribuído ao estabelecimento de um amplo conjunto de políticas industriais, de ciência e tecnologia e educacionais a partir de 2003, que colocaram a inovação no centro da agenda (MAZZUCATO; PENNA, 2016, p.58-75). Contudo, para os padrões internacionais, esses SIs ainda estão em um patamar intermediário de desenvolvimento, o que em parte se atribui ao caráter relativamente tardio da criação de universidades e instituições de pesquisa, bem como do processo de industrialização brasileiro, conforme assinalado por Suzigan e Albuquerque (2011, p.17). Embora, as capacitações tecnológicas e o desempenho na geração de inovações destes SIs sejam superiores ao de nações pouco industrializadas e ao de outras em patamar similar de industrialização, ainda estão bem aquém das que exercem liderança tecnológica.

\section{4 - Padrão de Interação Universidade-Empresa no Rio Grande do Sul}

A partir da caracterização de capacitações tecnológicas dos atores, essa seção orienta-se para o padrão de interação universidade-empresa (U-E) no Rio Grande do Sul e sua evolução recente. Nessa direção, uma primeira constatação é de que, em média, uma baixa proporção das empresas industriais gaúchas e brasileiras que inovaram entre 2006-08 e 2012-14, inferior a 22\%, atribuíram importância alta ou média às informações provenientes de Universidades ou Outros Centros de Ensino Superior (Gráfico 3). Para efeito de comparação, no triênio 2012-14, no Rio Grande do Sul foram considerados mais relevantes para a inovação - com grau alto ou médio - os conhecimentos oriundos de clientes/consumidores (80,3\%), de redes de informação informatizadas (76,7\%), de fornecedores $(70 \%)$ e de feiras/exposições $(64,9 \%)$, sendo que essa distribuição havia sido semelhante nos dois 
triênios anteriores ${ }^{18}$. Apesar disto, as instituições de ensino superior vieram em um processo de aumento de importância como fonte de informação para as firmas industriais do triênio 2006-08 para o 2009-11, com queda no período seguinte.

Gráfico 3: Participação das Empresas Industriais que Implementaram Inovações e que Classificaram como de "Alta" ou "Média" Relevância as Informações Provenientes de Universidades ou Outros Centros de Ensino Superior

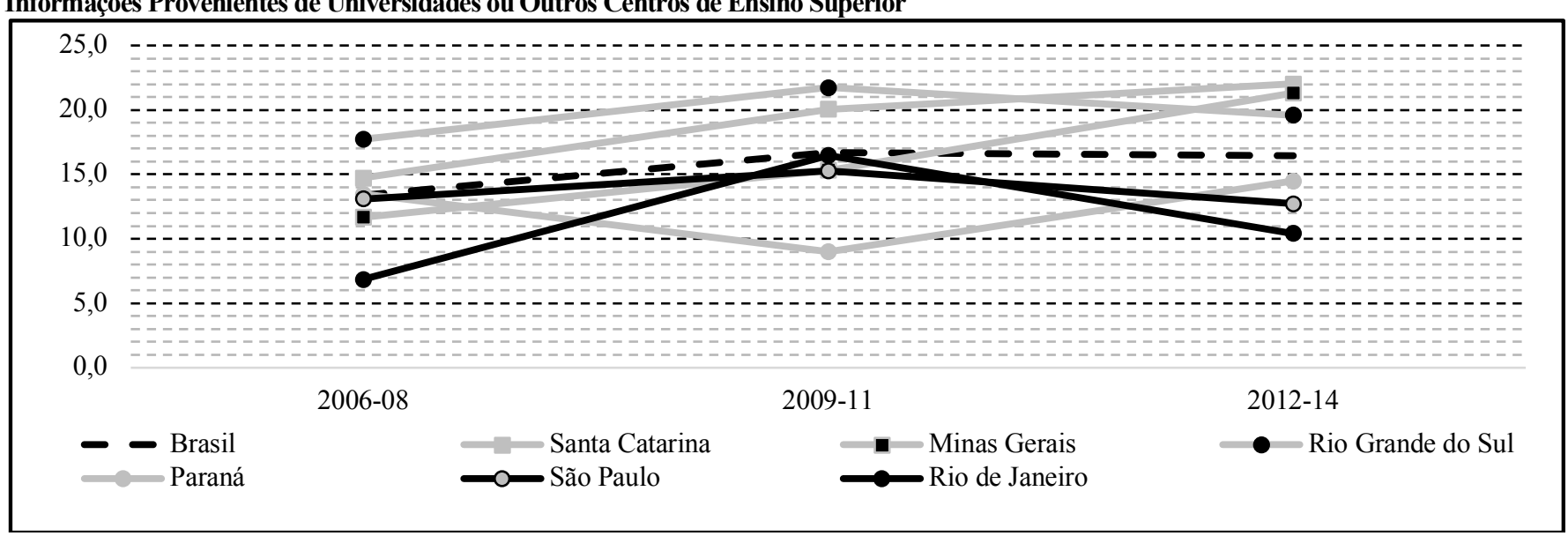

Fonte: IBGE (2010, 2013 e 2016).

Notas: Foram consideradas as empresas das indústrias extrativas e de transformação com 10 ou mais empregados que implementaram produto e/ou processo novo ou substancialmente aprimorado

Dentre as empresas industriais que introduziram inovações nos três triênios, a proporção das que realizaram desenvolvimento em cooperação com algum parceiro considerado de alta ou média relevância apresentou crescimento, tanto no Rio Grande do Sul, quanto na média nacional e em outros estados industrializados (Tabela 6). Em geral, constata-se no Brasil que as relações de cooperação relevantes dificilmente ultrapassam a marca de $20 \%$ do total que implementou inovações. Neste universo, constata-se que uma fração ainda menor do total das firmas industriais inovadoras realizou algum tipo de desenvolvimento conjunto com Universidades e institutos de pesquisas, avaliado como tendo importância alta ou média. Especificamente sobre a interação universidadeempresa, menos de $6 \%$ das empresas industriais inovadoras gaúchas e menos de $5 \%$ das brasileiras fizeram codesenvolvimento com universidades, considerado como tendo alta ou média importância nos três triênios. Entre as empresas industriais dos estados brasileiros, as do Rio Grande do Sul apresentaram as maiores taxas de inovações em parceria com universidades no período $2012-14$, de 5,2\%.

Tabela 6: Empresas industriais que implementaram inovações com outras organizações e que atribuíram grau alto ou médio de importância para a parceria por triênio, no Rio Grande do Sul e no Brasil

\begin{tabular}{l|c|c|c|c|c|c}
\hline \multicolumn{1}{c|}{ Unidades da } & \multicolumn{3}{|c|}{ Total Cooperação } & \multicolumn{3}{c}{ Cooperação com Universidades e Institutos de Pesquisa } \\
\multicolumn{1}{c|}{ Federação } & $2006-08$ & $2009-11$ & $2012-14$ & $2006-08$ & $2009-11$ & $2012-14$ \\
\hline Brasil & $\mathbf{1 0 , 1}$ & $\mathbf{1 5 , 9}$ & $\mathbf{1 4 , 3}$ & $\mathbf{3 , 0}$ & $\mathbf{4 , 8}$ & 3,5 \\
Rio Grande do Sul & 12,5 & 9,3 & 19,7 & 4,4 & 4,7 & 5,2 \\
São Paulo & 11,7 & 17,0 & 15,4 & 3,3 & 2,3 & 4,4 \\
Minas Gerais & 11,3 & 9,0 & 17,1 & 2,2 & 4,7 & 3,7 \\
Rio de Janeiro & 7,0 & 30,1 & 17,1 & 3,0 & 8,1 & 1,8 \\
Santa Catarina & 7,3 & 20,2 & 12,6 & 2,7 & 1,8 & 1,9 \\
Paraná & 11,2 & 20,3 & 14,1 & 2,4 & \\
\hline
\end{tabular}

Fonte: IBGE (2010, 2013 e 2016).

Notas: Foram consideradas as empresas das indústrias extrativas e de transformação com 10 ou mais empregados que implementaram produto e/ou processo novo ou substancialmente aprimorado no triênio analisado.

Para dimensionar o estágio atual das interações U-E no Rio Grande do Sul e no Brasil (Tabela 6), pode-se avaliá-lo em relação ao padrão observado em economias avançadas (Gráfico 4). Para países selecionados da Europa, em que pese diferenças metodológicas em relação à PINTEC ${ }^{19}$, em geral, as empresas industriais que

\footnotetext{
${ }^{18}$ Cálculos com base em dados das PINTECs 2008, 2011 e 2014 (IBGE, 2010, 2013 e 2016).

${ }^{19} \mathrm{Na}$ comparação entre a tabela 6 e o gráfico 4, o dado da PINTEC de número de empresas que interagiram com cada tipo de organização é computado e apresentado por categorias de importância "alta", "média" ou "baixa ou não relevante" do parceiro para a inovação, enquanto que o dado da CIS apresenta apenas as empresas inovadoras que interagiram com cada tipo de parceiro. Infere-se que a soma das categorias de "alta" e "média" importância da PINTEC seja uma aproximação razoável ao dado disponibilizado na CIS.
} 
inovaram em cooperação com outras organizações no triênio 2012-14 representaram mais de 20\% do total de inovadoras, acima do apresentado pelo Estado (19,7\%) e pelo País $(14,3 \%)$ nesse período. No que concerne à interação das empresas industriais com universidades e outras instituições de ensino superior, observa-se que, em geral, essa não chega a atingir 25\% do total daquelas que inovaram no período nos casos selecionados. Ainda assim, a proporção das empresas industriais europeias que cooperaram com universidades para inovar foi significativamente maior do que àquelas apresentadas em 2012-14 no Rio Grande do Sul (menos de 6\%) e no Brasil (menos de 5\%). Mesmo nações em patamar intermediário de industrialização, como Turquia ou Portugal, por exemplo, possuem uma maior proporção de interações universidade-empresa, do que aquelas apresentadas pelo RS e o BR. Essa proporção mais baixa no Brasil alinha-se ao diagnóstico de Suzigan e Albuquerque (2011, p.19) de que existam apenas alguns poucos "pontos de interação" universidade-empresa no País. Além dos aspectos mencionados, em que pese às variações causadas pelas características institucionais de cada sistema nacional de inovação, nota-se nos casos europeus, que aquelas nações conhecidas como tendo maiores níveis de desenvolvimento e de capacitações científicas e tecnológicas apresentaram maiores taxas de inovações oriundas de cooperação U-E (Gráfico 4). Esse padrão observado na Europa está de acordo com o preconizado pela literatura, que constata que maiores capacitações científicas e tecnológicas das empresas geram uma maior ocorrência de cooperação U-E para desenvolvimento de inovações.

Gráfico 4: Empresas da indústria de transformação de países da Europa que implementaram inovações desenvolvidas com relações de cooperação em geral e com universidades ou outras instituições de ensino superior no triênio 2012-2014

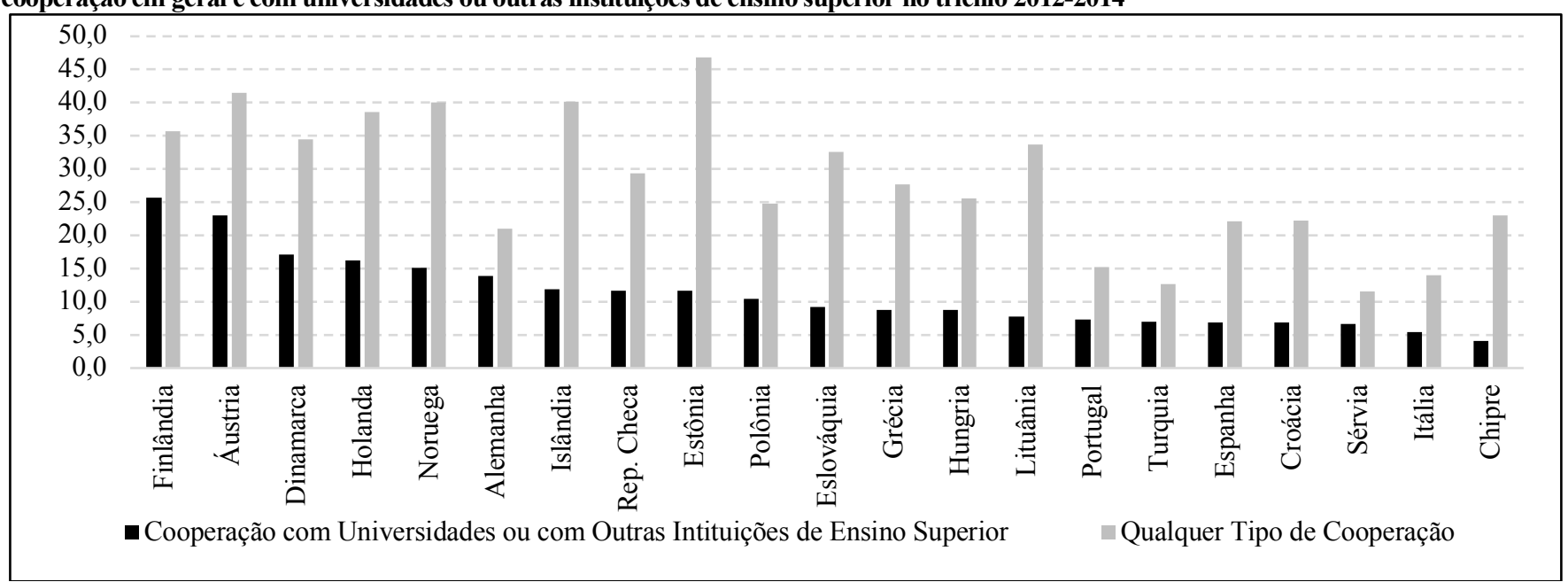

Fonte: Community Innovation Survey 2014 (EUROSTAT, 2017).

Notas: Considerou-se as empresas da indústria de transformação com 10 ou mais empregados dos países selecionados que implementaram inovações de produto ou de processo produtivo.

Conforme a literatura sobre interação universidade-empresa, a proximidade geográfica facilita a interação, o que também se constata no Brasil (GARCIA et al., 2014, p.108-110). No Rio Grande do Sul, 43,5\% das interações U-E concentram-se em até $50 \mathrm{~km}$ de distância, o que aponta para a relevância de sistemas locais de inovação para o desenvolvimento tecnológico de empresas industriais (COSTA; RUFFONI; PUFFAL, 2011, p.223). Inclusive, observa-se que as instituições de pesquisa locais, em geral, possuem algumas atividades de $P \& D$ e de extensão voltadas às empresas de sua região. Apesar disto, em recente pesquisa realizada pela Fundação de Economia e Estatística - FEE/RS sobre determinantes da competitividade de empresas em onze aglomerações produtivas e arranjos produtivos locais do Rio Grande do Sul, se constatou uma baixa interação U-E em alguns desses casos (MACADAR; COSTA, 2016, p.583). Em geral, nos casos estudados foram as empresas de portes médio e grande, dotadas de maiores capacitações e próximas à fronteira tecnológica em suas atividades ${ }^{20}$, que interagiram mais com as universidades. Logo, a baixa proporção de interações U-E em relação ao observado entre nações industrializadas indica que as relativamente baixas capacitações tecnológicas na indústria no Rio Grande do Sul e no Brasil, sobretudo em número de pesquisadores pós-graduados, seja um dos principais fatores explicativos para esse comportamento, por gerar, entre outros, um distanciamento cognitivo entre esses agentes. Nesse sentido, Rapini, Chiarini e Bittencourt (2017, p.13) também constatam a nível nacional que o déficit de

\footnotetext{
${ }^{20}$ Também foi constatado que algumas dessas empresas integravam verticalmente a fabricação de itens de maior sofisticação devido a falta de fornecedores capacitados.
} 
pessoal qualificado, tanto na indústria quanto nas universidades, seja um dos impeditivos para a ocorrência de interações. Entretanto, mesmo que a cooperação das empresas industriais para inovar com as universidades e outras instituições de ensino superior sejam relativamente baixas, ela vem aumentando, passando de 4,4\% em 2006-08 para 5,2\% em 2012-14 no Rio Grande do Sul, enquanto que no Brasil esta passou de 3,0\% para 3,5\%.

Igualmente, constata-se que tanto o número total de grupos de pesquisa, quanto daqueles que interagiram com empresas se elevaram no período ${ }^{21}$. Em termos de taxa de crescimento ${ }^{22}$ de 2008 para 2014, a do total dos grupos de pesquisa foi de 43,9\% no Rio Grande do Sul e de 55,4\% no Brasil, enquanto que a daqueles com relacionamento com empresas foi de $171,3 \%$ no Estado e de $242,9 \%$ no País. Logo, verifica-se que a proporção de grupos de pesquisa com interação com empresas ganhou importância no Brasil, sendo que, nesse quesito, o Estado ficou com a segunda posição em 2010 e 2014 (Tabela 7). Isto indica estar havendo uma maior aproximação entre universidades e empresas nessas áreas geográficas, o que também pode ser creditado à evolução dos instrumentos de política científica e tecnológica, sobretudo na última década (DE NEGRI; CAVALCANTE; ALVES, 2015, p.16).

Tabela 7: Número de grupos de pesquisa que relataram pelo menos um relacionamento com empresas, segundo a Unidade da Federação

\begin{tabular}{|c|c|c|c|c|c|c|c|c|c|}
\hline \multirow[b]{3}{*}{ UF do grupo } & \multicolumn{9}{|c|}{ I0caingauo } \\
\hline & \multicolumn{3}{|c|}{2008} & \multicolumn{3}{|c|}{2010} & \multicolumn{3}{|c|}{2014} \\
\hline & $\begin{array}{c}\text { Com } \\
\text { relacão }(R)\end{array}$ & $\begin{array}{c}\text { Total de } \\
\text { grupos }(\mathrm{T})\end{array}$ & $\%(\mathrm{R}) /(\mathrm{T})$ & $\begin{array}{c}\text { Com } \\
\text { relacão }(R)\end{array}$ & $\begin{array}{c}\text { Total de } \\
\text { grupos }(\mathrm{T})\end{array}$ & $\%(\mathrm{R}) /(\mathrm{T})$ & $\begin{array}{c}\text { Com } \\
\text { relacão }(R)\end{array}$ & $\begin{array}{c}\text { Total de } \\
\text { grupos }(\mathrm{T})\end{array}$ & $\%(\mathrm{R}) /(\mathrm{T})$ \\
\hline Brasil & 2.726 & 22.797 & 12,0 & 3.506 & 27.523 & 12,7 & 9.348 & 35.424 & 26,4 \\
\hline São Paulo & 576 & 5.938 & 14,0 & 747 & 6.359 & 18,9 & 1.922 & 7.278 & 26,4 \\
\hline Rio de Janeiro & 286 & 2.779 & 10,3 & 358 & 3.313 & 10,8 & 1.216 & 4.147 & 29,3 \\
\hline Rio Grande do Sul & 345 & 2.304 & 15,0 & 404 & 2.677 & 15,1 & 936 & 3.315 & 28,2 \\
\hline Minas Gerais & 300 & 2.135 & 14,1 & 396 & 2.848 & 13,9 & 920 & 3.482 & 26,4 \\
\hline Paraná & 242 & 1.915 & 13,7 & 302 & 2.264 & 13,3 & 686 & 3.011 & 22,8 \\
\hline Outros & 977 & 7.726 & 12,6 & 1.299 & 10.062 & 12,9 & 3.668 & 14.191 & 25,8 \\
\hline
\end{tabular}

Fonte: $\mathrm{CNPq}(2017 \mathrm{~b})$.

Notas: Foram contabilizados os grupos de pesquisa e aqueles com no mínimo um relacionamento com empresas. Um grupo pode manter relacionamento com mais de uma empresa no ano. O CNPq não realizou recenseamento no ano de 2012.

Em 2008 e em 2010, as grandes áreas do conhecimento com maior número de grupos de pesquisa que mantiveram interações com empresas no Rio Grande do Sul foram as engenharias, seguidas das ciências agrárias e as da saúde (Tabela 8). Estas também foram as mais acessadas pelas empresas gaúchas e brasileiras, apresentando maior densidade de interações por grupo de pesquisa, o que já era de se esperar, dada a natureza do conhecimento em que essas áreas estão envolvidas. Como constatado anteriormente, alguns cursos de pósgraduação em engenharias, ciências biológicas e da saúde destacam-se como sendo de excelência. Este padrão indica existir uma associação próxima entre as expertises e linhas de pesquisa das universidades e institutos de pesquisa e a estrutura da matriz produtiva do Estado, a qual possui expressiva participação dos setores de base metalomecânica (automotivo, máquinas e equipamentos, produtos de metal e outras) e da cadeia produtiva de fabricação de alimentos (atividades do setor primário e agroindústrias).

Tabela 8: Interações de grupos de pesquisa do Rio Grande do Sul com empresas brasileiras por grande área do conhecimento

\begin{tabular}{|c|c|c|c|c|c|c|c|c|c|c|}
\hline \multirow{3}{*}{ Grande área do conhecimento } & \multicolumn{5}{|c|}{2008} & \multicolumn{5}{|c|}{2010} \\
\hline & \multicolumn{2}{|c|}{ Grupos } & \multicolumn{2}{|c|}{ Empresas } & \multirow{2}{*}{$\frac{\text { Densidade }}{(\mathrm{E} / \mathrm{G})}$} & \multicolumn{2}{|c|}{ Grupos } & \multicolumn{2}{|c|}{ Empresas } & \multirow{2}{*}{$\begin{array}{c}\text { Densidade } \\
(\mathrm{E} / \mathrm{G})\end{array}$} \\
\hline & $\mathrm{N}^{\mathrm{o}}$ & $\%$ & $\mathrm{~N}^{\mathrm{o}}$ & $\%$ & & $\mathrm{~N}^{\mathrm{o}}$ & $\%$ & $\mathrm{~N}^{\mathrm{o}}$ & $\%$ & \\
\hline $\begin{array}{l}\text { TOTAIS } \\
\end{array}$ & 345 & 100,0 & 683 & 100,0 & 1,98 & 404 & 100,0 & 829 & 100,0 & 2,05 \\
\hline - Engenharias & 113 & 32,8 & 288 & 42,2 & 2,55 & 128 & 31,7 & 311 & 37,5 & 2,43 \\
\hline - Ciências Agrárias & 66 & 19,1 & 112 & 16,4 & 1,70 & 82 & 20,3 & 175 & 21,1 & 2,13 \\
\hline - Ciências Exatas e da Terra & 40 & 11,6 & 74 & 10,8 & 1,85 & 45 & 11,1 & 87 & 10,5 & 1,93 \\
\hline - Ciências da Saúde & 40 & 11,6 & 91 & 13,3 & 2,28 & 53 & 13,1 & 113 & 13,6 & 2,13 \\
\hline - Ciências Biológicas & 34 & 9,9 & 47 & 6,9 & 1,38 & 41 & 10,1 & 58 & 7,0 & 1,41 \\
\hline - Outras & 52 & 15,1 & 71 & 10,4 & 1,37 & 55 & 13,6 & 85 & 10,3 & 1,55 \\
\hline
\end{tabular}

Fonte: $\mathrm{CNPq}(2017 \mathrm{a})$.

Notas: As empresas mencionadas não estão localizadas, necessariamente, no mesmo Estado do grupo. O CNPq descontinuou o Plano Tabular do

Diretório de Grupos de Pesquisa após 2010.

\footnotetext{
${ }^{21}$ Os dados do Diretório de Grupos de Pesquisa do CNPq se referem às interações com empresas que são declaradas pelo líder do grupo de pesquisa. Pode existir algum grau de subestimação no número de interações, sobretudo em determinadas áreas, por estas não terem sido informadas. Contudo, considera-se que o número de interações informadas se constitua em uma proxy fidedigna para o total de interações entre grupos de pesquisa e empresas.

${ }_{22}$ Cálculos com base nos dados da Tabela 7.
} 
Segundo a indicação de líderes de grupos de pesquisa no Rio Grande do Sul, os motivos predominantes para interação com empresas industriais brasileiras foram majoritariamente a "pesquisa científica com considerações de uso imediato dos resultados", seguida pela "transferência de tecnologia desenvolvida pelo grupo para o parceiro" e pela "pesquisa científica sem considerações de uso imediato dos resultados", cujo somatório ${ }^{23}$ resulta em cerca de 62\% do total informado em 2008 e em 2010 (Tabela 9). Em especial, esta distribuição de motivos para a interação U-E observada no Rio Grande do Sul se assemelha ao padrão identificado na literatura. Isto é, em geral, os tipos de relacionamentos buscados pelas empresas industriais com organizações de pesquisa gaúchas objetivam complementar lacunas em suas capacitações tecnológicas ou solucionar problemas no desenvolvimento de inovações, bem como a obter resultados no curto prazo.

Tabela 9: Tipos de relacionamento predominantes entre grupos de pesquisa do Rio Grande do Sul e empresas industriais brasileiras

\begin{tabular}{|c|c|c|c|c|}
\hline \multirow{2}{*}{ Tipos de relacionamentos } & \multicolumn{2}{|c|}{2008} & \multicolumn{2}{|c|}{2010} \\
\hline & $\mathrm{N}^{\mathrm{o}}$ & $\%$ & $\mathrm{~N}^{\mathrm{o}}$ & $\%$ \\
\hline Total & 560 & 100,0 & 556 & 100,0 \\
\hline - Pesquisa científica com considerações de uso imediato dos resultados & 175 & 31,3 & 183 & 32,9 \\
\hline - Transferência de tecnologia desenvolvida pelo grupo para o parceiro & 101 & 18,0 & 94 & 16,9 \\
\hline - Pesquisa científica sem considerações de uso imediato dos resultados & 74 & 13,2 & 72 & 12,9 \\
\hline $\begin{array}{l}\text { - Fornecimento, pelo parceiro, de insumos materiais para as atividades de pesquisa do grupo sem } \\
\text { vinculação a um projeto específico de interesse mútuo }\end{array}$ & 28 & 5,0 & 53 & 9,5 \\
\hline $\begin{array}{l}\text { - Atividades de engenharia não-rotineira inclusive o desenvolvimento de protótipo cabeça de série ou } \\
\text { planta-piloto para o parceiro }\end{array}$ & 44 & 7,9 & 30 & 5,4 \\
\hline - Outros & 138 & 24,6 & 124 & 22,3 \\
\hline
\end{tabular}

Fonte: $\mathrm{CNPq}(2017 \mathrm{a})$.

Notas: Foram admitidas até três formas predominantes de relacionamento. As empresas mencionadas não estão localizadas, necessariamente, no mesmo Estado do grupo. O CNPq descontinuou o Plano Tabular do Diretório de Grupos de Pesquisa após 2010.

Dentre as empresas gaúchas que cooperaram com grupos de pesquisa no Estado ou no País, as industriais representaram 40,5\% em 2008 e 40,3\% em 2010. Os setores de atividades industriais que individualmente mostraram o maior número de interações em relação ao total da indústria foram o de "máquinas e equipamentos" e o de "produtos químicos" (Tabela 10). No agregado de atividades industriais, o destaque pertence às de base metalomecânica. Um indicador mais representativo da importância setorial das interações U-E consiste na sua proporção em relação ao total de empresas do respectivo setor no Estado. Sob essa ótica, aqueles com maiores percentuais de empresas que cooperaram com grupos de pesquisa foram os de "produtos farmoquímicos e farmacêuticos"; de "equipamentos de informática, produtos eletrônicos e ópticos"; de "produtos químicos"; de "metalurgia"; e de "máquinas e equipamentos". Note-se que esta distribuição se aproxima daquela observada na taxonomia de intensidade de esforço tecnológico da OCDE, pois a maior densidade de interações ocorre nos setores classificados como de "alta" ou de "média-alta", com exceção da metalurgia (média-baixa). Em outras palavras, os setores que em média possuem maior intensidade tecnológica são também os que, em geral, apresentaram maior proporção de empresas com interações U-E. Assim, a baixa participação relativa de setores high-tech $(33,7 \%)$, bem como de empresas de médio e grande portes $(3,4 \%)$, indica que a característica da estrutura da matriz industrial do Estado seja um dos determinantes da baixa ocorrência de interações universidade-empresa. Observe-se que Bastos e Britto (2017, p.55-56) fazem constatação semelhante para o Brasil. Por fim, observe-se que o número de empresas industriais que mantiveram relacionamentos se reduziu de 2008 para 2010, em 3,9\% para as industriais e em 3,3\% para o total, o que pode ser atribuído às incertezas associadas à crise financeira mundial (2008-10).

\footnotetext{
${ }^{23}$ Cálculos com base em dados da Tabela 9.
} 
Tabela 10: Empresas industriais do Rio Grande do Sul que cooperaram com grupos de pesquisa no Brasil por setor de atividade, total de empresas no setor e proporção de interações U-E

\begin{tabular}{|c|c|c|c|c|c|c|c|c|}
\hline \multirow{3}{*}{ Divisão de Atividade CNAE 2.0} & \multicolumn{4}{|c|}{2008} & \multicolumn{4}{|c|}{2010} \\
\hline & \multicolumn{2}{|c|}{ Cooperaram } & \multirow{2}{*}{$\begin{array}{r}\text { Total } \\
\mathrm{N}^{\mathrm{o}}(\mathrm{T})\end{array}$} & \multirow{2}{*}{$\%-(\mathrm{C} / \mathrm{T})$} & \multicolumn{2}{|c|}{ Cooperaram } & \multirow{2}{*}{$\begin{array}{r}\text { Total } \\
\mathrm{N}^{\mathrm{o}}(\mathrm{T})\end{array}$} & \multirow{2}{*}{$\%-(\mathrm{C} / \mathrm{T})$} \\
\hline & $\mathrm{N}^{\mathrm{o}}(\mathrm{C})$ & $\%$ & & & $\mathrm{~N}^{\mathrm{o}}(\mathrm{C})$ & $\%$ & & \\
\hline Total & 632 & $\mathrm{~N} / \mathrm{A}$ & 424.775 & 0,15 & 611 & $\mathrm{~N} / \mathrm{A}$ & 452.891 & 0,13 \\
\hline -Indústrias & 256 & 100,0 & 50.845 & 0,50 & 246 & 100,0 & 52.931 & 0,46 \\
\hline --Prod. farmoquímicos e farmacêuticos & 8 & 3,1 & 71 & 11,27 & 8 & 3,3 & 65 & 12,31 \\
\hline --Equip. info., prod. eletrônicos e ópticos & 26 & 10,2 & 457 & 5,69 & 14 & 5,7 & 473 & 2,96 \\
\hline --Produtos químicos & 33 & 12,9 & 989 & 3,34 & 27 & 11,0 & 974 & 2,77 \\
\hline --Metalurgia & 14 & 5,5 & 690 & 2,03 & 11 & 4,5 & 649 & 1,69 \\
\hline --Máq., aparelhos e mater. elétricos & 9 & 3,5 & 629 & 1,43 & 8 & 3,3 & 618 & 1,29 \\
\hline --Máquinas e equipamentos & 45 & 17,6 & 2.471 & 1,82 & 34 & 13,8 & 2.655 & 1,28 \\
\hline --Borracha e plástico & 21 & 8,2 & 1.957 & 1,07 & 18 & 7,3 & 1.949 & 0,92 \\
\hline --Produtos alimentícios & 14 & 5,5 & 6.023 & 0,23 & 30 & 12,2 & 6.384 & 0,47 \\
\hline --Produtos de metal & 29 & 11,3 & 6.626 & 0,44 & 17 & 6,9 & 7.190 & 0,24 \\
\hline --Couros e calçados & 12 & 4,7 & 6.492 & 0,18 & 15 & 6,1 & 6.420 & 0,23 \\
\hline
\end{tabular}

Fonte: CNPq (2017a) e IBGE (2017a).

Notas: A área geográfica da empresa foi informada pelo líder do grupo e pesquisa. Os grupos não estão localizados, necessariamente, no Rio Grande do Sul. O CNPq descontinuou o Plano Tabular do Diretório de Grupos de Pesquisa após 2010.

\section{Consideracões Finais}

A interação universidade-empresa é um elemento importante do funcionamento de Sistemas de Inovação e na evolução do conhecimento científico e tecnológico na sociedade, afetando em âmbito mais amplo o processo de desenvolvimento econômico. Os resultados encontrados neste estudo fornecem informações para orientar a elaboração de política industrial e de ciência e tecnologia, bem como à tomada de decisão empresarial, visando o fortalecimento do SI do Rio Grande do Sul e seus efeitos positivos sobre a competitividade das empresas e o crescimento econômico.

Quando avaliadas no período 2008-14, se observa que o desempenho das empresas industriais, em termos de suas capacitações tecnológicas (investimentos em inovação, recursos humanos e infraestrutura à P\&D), e o das universidades, quanto ao seu potencial para a formação de recursos humanos e de realização de pesquisas, encontram-se posicionadas acima da média nacional. Além disto, se observa em diversos indicadores das capacitações de empresas industriais e de universidades e outras instituições de pesquisa uma tendência de melhoria absoluta e relativa no período 2008-14, tanto no Estado quanto no País. Essa tendência pode ser atribuída às políticas de educação superior, de ciência, tecnologia, e industriais e de inovação aplicadas no País desde 2003. Esse processo de melhora tem se mostrado relativamente mais intenso no Estado. Entretanto, em que pese esses destaques positivos, é de se observar que o sistema de inovação do Rio Grande do Sul situa-se em patamar inferior àquele apresentado por países industrializados, situando-se em nível intermediário de desenvolvimento. Isto mostra que existem espaços para que tanto as empresas industriais quanto as universidades aprimorarem suas capacitações científicas e tecnológicas, o que fortaleceria o SI estadual. Contudo, há uma assimetria entre esses agentes, cuja situação aparenta ser mais crítica para as empresas industriais do que para as universidades. Isso se evidencia em alguns indicadores importantes para o processo de desenvolvimento de inovações, cujos percentuais em 2014 podem se considerar como relativamente baixos, como no caso dos dispêndios em atividades internas de $\mathrm{P} \& \mathrm{D}$, de pesquisadores pós-graduados e de empresas industriais que inovaram com gastos contínuos em $\mathrm{P} \& \mathrm{D}$ interno. Esse fraco desempenho acaba afetando negativamente a competitividade na indústria do Estado, sobretudo, em seus segmentos de maior intensidade tecnológica.

Pode-se considerar que a interação universidade-empresa no Rio Grande do Sul ainda se apresenta pouco frequente, uma vez que menos de $22 \%$ das empresas industriais inovadoras atribuíram alta ou média relevância às informações provenientes de universidades e demais instituições de pesquisa nos três triênios analisados, assim como menos de $6 \%$ desse total declararam terem desenvolvido inovações em parceria com estas organizações. Esta intensidade de interações universidade-empresa, embora acima da média nacional, está bem aquém daquela constatada em economias desenvolvidas. Como aspecto positivo, porém, nos últimos anos, percebe-se uma tendência de elevação da importância da interação U-E, indicando estar ocorrendo uma maior aproximação das universidades e instituições de pesquisa com empresas industriais no Rio Grande do Sul. Ademais, o número de grupos de pesquisa que interagiu com empresas se elevou a uma taxa superior à do total de grupos, ganhando 
maior representatividade. Nesse processo, o padrão observado nas interações U-E manteve-se como sendo semelhante àquele apontado na literatura, isto é, em geral, as empresas industriais do Estado procuram este tipo de relação para complementar alguma lacuna em suas capacitações ou para solucionar problemas tecnológicos, buscando obter resultados de aplicação imediata. Portanto, ainda existe um baixo acesso pelas empresas aos conhecimentos e recursos gerados nas universidades, de modo que há espaço para uma maior aproximação desses agentes e para a intensificação de suas relações.

A menor proporção de interações U-E em relação aos países mais industrializados indica que existem alguns fatores atuando como limitadores. Dentre os principais que foram identificados nesse estudo, sem ter a pretensão de esgotar essa listagem, se entende que sejam: (1) as relativamente baixas capacitações tecnológicas das empresas industriais gaúchas, sobretudo em qualificação de recursos humanos, com reduzido número e baixa proporção de pesquisadores pós-graduados; (2) a pequena proporção de empresas que executam atividades de P\&D em caráter contínuo; (3) a conhecida distância da fronteira tecnológica internacional em alguns segmentos de "alta" e de "média-alta" intensidade tecnológica - tais como na indústria farmacêutica, na produção de tecnologias de informação e comunicação e de componentes eletrônicos; e (4) a estrutura da matriz produtiva industrial, com predominância de atividades low-tech, somando-se à baixa incidência de médias e grandes empresas nessa estrutura.

\section{$\underline{\text { Referências }}$}

ANTUNES JÚNIOR, José A. V.; HORN, Carlos Henrique; PELLEGRIN, Ivan; VAZ, Ibes Eron A. (orgs.). Remando Contra a Maré: a Política Industrial e de Desenvolvimento Econômico no Rio Grande do Sul (2011-2014). Porto Alegre/RS: Bookman, 376p., 2017.

BASTOS, Carlos P.; BRITTO, Jorge. "Inovação e geração de conhecimento científico e tecnológico no Brasil: uma análise dos dados de cooperação da Pintec segundo porte e origem de capital" In: Revista Brasileira de Inovação, Vol. 16, Nº1, p.35-62, janeiro/junho. Campinas (SP): Finep, 2017.

BERNARDINI, Rafael (coord.); et. al. Ciência, tecnologia e inovação no Rio Grande do Sul: indicadores selecionados 2014. Porto Alegre/RS/BR: FEE, 80p., 2014.

BRASIL. Ministério do Trabalho e Emprego (MTE). Relação de Informações Sociais (RAIS). Brasília, DF, 2017. Acesso em 05 abr. 2017.

BURCHARTH, Ana L. L. A. "What Drives the Formation of Technological Cooperation Between University and Industry in Less-Developed Innovation Systems? Evidence From Brazil” In: Revista Brasileira de Inovação, Vol. 10, No1, p.101-128, janeiro/junho. Campinas (SP): Finep, 2011.

CAMPOS, André L. "A review of the influence of long-term patterns in research and technological development (R\&D) formalisation on university-industry links". In: Revista Brasileira de Inovação, Vol.9, №2, p.379410, julho/dezembro. Rio de Janeiro (RJ): Finep, 2010.

CONSELHO NACIONAL DE DESENVOLVIMENTO CIENTÍFICO E TECNOLÓGICO (CNPq). Diretório dos Grupos de Pesquisa no Brasil. Plano Tabular. 2017. Disponível em: http://plsql1.cnpq.br/planotabular/. Acesso em: 10 jan. 2017a.

CONSELHO NACIONAL DE DESENVOLVIMENTO CIENTÍFICO E TECNOLÓGICO (CNPq). Diretório dos Grupos de Pesquisa no Brasil. Súmula Estatística. 2017. Disponível em: http://attes.cnpq.br/web/dgp/sobre14. Acesso em: 10 jan. $2017 \mathrm{~b}$.

COORDENAÇÃO DE APERFEIÇOAMENTO DE PESSOAL DE NÍVEL SUPERIOR (CAPES). Sobre a avaliação. 2017. Disponível em http://www.capes.gov.br/avaliacao/sobre-a-avaliacao. Acesso em: 20 abr. $2017 \mathrm{a}$.

COORDENAÇÃO DE APERFEIÇOAMENTO DE PESSOAL DE NÍVEL SUPERIOR (CAPES). GEOCAPES: Sistema de Informações Georreferenciadas - 2015. Disponível em: http://geocapes.capes.gov.br/geocapes2/ Acesso em: 27 fev. $2017 \mathrm{~b}$.

COSTA, Achyles B.; RUFFONI, Janaina; PUFFAL, Daniel. "Proximidade geográfica e interação universidadeempresa no Rio Grande do Sul”. In: Revista de Economia, Vol. 37, No especial, p.213-238, Curitiba/PR: Editora UFPR, 2011. 
DE NEGRI, Fernanda; CAVALCANTE, Luiz R.; ALVES, Patrick A. "University-enterprise interaction in Brazil: The role of the public research infrastructure". In: Discussion paper/IPEA, 42p. Brasília/Rio de Janeiro: Ipea, 2015.

EDQUIST, Charles. "Systems of Innovation Approaches - Their Emergence and Characteristics". In: EDQUIST, Charles (ed.). Systems of Innovation: Technologies, Institutions and Organization. Nova Yorque/EUA: Routledge. p.1-35, 2011.

EUROSTAT. Community Innovation Survey 2014. Luxembourg: EUROPEAN COMMISSION, 2017. Disponível em: http://ec.europa.eu/eurostat. Acesso em: 07 mar. 2017.

FREEMAN, Christopher. "Technological Infraestructure and International Competitiveness". In: FREEMAN, Christopher. Systems of Innovation: Selected Essays in Evolutionary Economics. Cheltenham/Reino Unido: Edward Elgar Publishing Limited, p.6-37, 2008.

FREEMAN, Christopher. "Formal Scientific and Technical Institutions in the National Systems of Innovation". In: LUNDVALL, Bengt-Ake (ed.). National Systems of Innovation: Toward a Theory of Innovation and Interactive Learning. Londres/Reino Unido: Anthem Press. p.173-192, 2010.

FUNDAÇAO DE ECONOMIA E ESTATISTICA SIEGFRIED EMANUEL HEUSER (FEE). Estrutura do Valor Adicionado por Setores de Atividade. Porto Alegre/RS: FEE, Centro de Indicadores Econômicos e Sociais, Núcleo de Contas Regionais. 2016.

GARCIA, Renato; ARAUJO, Veneziano A.; MASCARINI, Suelene; SANTOS, Emerson G. "Efeitos da Qualidade da Pesquisa Acadêmica sobre a Distância Geográfica das Interações Universidade-Empresa". In: Estudos Econômicos, Vol. 44, Nº1, p.105-132, jan.-mar., São Paulo/SP: FEA-USP, 2014.

HODGSON, Geoffrey M. "The Approach of Institutional Economics". In: Journal of Economic Literature, vol. 36, nº1, march, p.166-192. Pittsburgh/EUA: American Economic Association, 1998.

INSTITUTO BRASILEIRO DE GEOGRAFIA E ESTATÍSTICA (IBGE). Pesquisa de inovação (PINTEC)2008. Rio de Janeiro, 2010.

INSTITUTO BRASILEIRO DE GEOGRAFIA E ESTATÍSTICA (IBGE). Pesquisa de inovação (PINTEC)2011. Rio de Janeiro, 2013.

INSTITUTO BRASILEIRO DE GEOGRAFIA E ESTATÍSTICA (IBGE). Pesquisa de inovação (PINTEC)2014. Rio de Janeiro, 2016.

INSTITUTO BRASILEIRO DE GEOGRAFIA E ESTATÍSTICA (IBGE). Estatísticas do cadastro central de empresas - CEMPRE. In: Sistema IBGE de Recuperação Automática - SIDRA, 2017. Disponível em: https://sidra.ibge.gov.br/pesquisa/cempre/quadros/brasil/2014. Acesso em: 12 abr. $2017 \mathrm{a}$.

INSTITUTO BRASILEIRO DE GEOGRAFIA E ESTATÍSTICA (IBGE). Pesquisa Industrial Anual Empresa - 2014. In: Sistema de Recuperação Automática - SIDRA, 2017. Disponível em: https://sidra.ibge.gov.br/pesquisa/pia-empresa/quadros/brasil/2014. Acesso em: 06 fev. $2017 \mathrm{~b}$.

INSTITUTO BRASILEIRO DE GEOGRAFIA E ESTATÍSTICA (IBGE). Produto Interno Bruto dos Municípios. In: Sistema IBGE de Recuperação Automática - SIDRA, 2017. Disponível em: https://sidra.ibge.gov.br/pesquisa/pib-munic/tabelas. Acesso em: 12 abr. 2017c.

INSTITUTO DE PESQUISA ECONOMICA APLICADA (IPEA). IPEADATA: IGP-DI - geral - índice (ago. 1994 = 100)/Fundação Getúlio Vargas (FGV). 2017. Disponível em: http://www.ipeadata.gov.br. Acesso em: 10 fev. 2017.

INSTITUTO NACIONAL DE ESTUDOS E PESQUISAS EDUCACIONAIS ANISIO TEIXEIRA. Sinopse Estatística da Educação Superior: 2008 a 2014. Brasília/DF: INEP, 2015. Disponível em: http://portal.inep.gov.br/basica-censo-escolar-sinopse-sinopse. Acesso em $21 \mathrm{fev} .2017 \mathrm{a}$.

INSTITUTO NACIONAL DE ESTUDOS E PESQUISAS EDUCACIONAIS ANISIO TEIXEIRA. Índice Geral de Cursos (IGC) - 2014. Brasília/DF: INEP, 2015. Disponível em: http://portal.inep.gov.br/indicegeral-de-cursos-igc-. Acesso em 21 fev. 2017b.

LUNDVALL, Bengt-Ake. "Introduction”. In: LUNDVALL, Bengt-Ake (ed.). National Systems of Innovation: Toward a Theory of Innovation and Interactive Learning. Londres/Reino Unido: Anthem Press. p.1-19, 2010.

MACADAR, B. M. de; COSTA, R. M. da. D. Uma avaliação geral das aglomerações produtivas e dos APLs selecionados no Rio Grande do Sul. In: MACADAR, B. M. de; COSTA, R. M. da. (Org.). Aglomerações e Arranjos Produtivos Locais no Rio Grande do Sul. Porto Alegre: FEE, p.566-584, 2016. 
MAZZUCATO, Mariana. O Estado Empreendedor: Desmascarando o Mito do Setor Público vs. Setor Privado. Tradução de Elvira Serapicos. São Paulo/SP: Portfólio-Penguin, $1^{\text {a }}$ ed., 340p., 2014.

MAZZUCATO, Mariana; PENNA, Caetano. "The Brazilian Innovation System: A Mission-Oriented Policy Proposal". Temas Estratégicos para o Desenvolvimento do Brasil, $n^{\circ} 1$, mar., 119p.. Avaliação de Programas em CT\&I. Brasília/DF: Centro de Gestão e Estudos Estratégicos, 119p., 2016.

MOWERY, David C.; SAMPAT, Bhaven N. "Universities in National Innovation Systems". In: FAGERBERG, Jan; MOWERY, David C.; NELSON, Richard R. (eds.). The Oxford Handbook of Innovation. Nova Yorque/EUA: Oxford University Press Inc., p.209-239, 2005.

NELSON, Richard; ROSENBERG, Nathan. 'Science, Technological Advance and Economic Growth'. In: CHANDLER, Alfred; HAGSTRÖM, Peter; e SÖVELL, Örjan. The Dynamic Firm: The Role of Technology, Strategy, Organization and Regions. Oxford/NY/EUA: Oxford University Press, p.45-59, 1999.

ORGANIZAÇÃO PARA A COOPERAÇÃO E DESENVOLVIMENTO ECONÔMICO (OCDE). ISIC Rev.3 technology intensity definition: classification of manufacturing industries into categories based on r\&d intensities. Paris, 2011.

ORGANIZAÇÃO PARA A COOPERAÇÃO E DESENVOLVIMENTO ECONÔMICO (OCDE). OECD.Stat. Business enterprise R-D expenditure by industry (ISIC 4). Paris, 2017. Disponível em: http://stats.oecd.org. Acesso em: 13 jun. 2017a.

ORGANIZAÇÃO PARA A COOPERAÇÃO E DESENVOLVIMENTO ECONÔMICO (OCDE). OECD.Stat. Gross Domestic Product (GDP). Paris, 2017. Disponível em: http://stats.oecd.org. Acesso em: 13 jun. $2017 \mathrm{~b}$.

RAPINI, Márcia S.; CHIARINI, Tulio; BITTENCOURT, Pablo F. "Obstacles to innovation in Brazil: The lack of qualified individuals to implement innovation and establish university-firm interactions". In: Industry and Higher-Education, XX (X). Londres/RU: Sage Publishing, p.1-16, 2017.

SCHAEFFER, Paola R.; RUFFONI, Janaina; PUFFAL, Daniel. "Razões, benefícios e dificuldades da interação universidade-empresa". In: Revista Brasileira de Inovação, Vol. 14, No1, p.105-134, janeiro/junho. Campinas (SP): Finep, 2015.

SERVIÇO BRASILEIRO DE APOIO ÀS MICRO E PEQUENAS EMPRESAS (SEBRAE). Critério para classificação de empresas: MEI - ME - EPP. 2017. Disponível em: http://www.sebraesc.com.br/leis/default.asp?vcdtexto=4154 . Acesso em 07 mar. 2017.

SMITH, Keith. "Economic Infraestructures and Innovation Systems". In: EDQUIST, Charles (ed.). Systems of Innovation: Technologies, Institutions and Organization. Nova Yorque/EUA: Routledge. p.86-106, 2011.

SUZIGAN, Wilson; ALBUQUERQUE, Eduardo M. "A interação entre universidades e empresas em perspectiva histórica no Brasil”. In: SUZIGAN, Wilson; ALBUQUERQUE, Eduardo M.; CARIO, Silvio A. F. (eds.). Em Busca da Inovação: Interação Universidade-Empresa no Brasil. Belo Horizonte: Autêntica Editora, (Coleção Economia Política e Sociedade, 3), p.17-44, 2011.

SUZIGAN, Wilson; ALBUQUERQUE, Eduardo M.; CARIO, Silvio A. F. "Introdução”. In: SUZIGAN, Wilson; ALBUQUERQUE, Eduardo M.; CARIO, Silvio A. F. (eds.). Em Busca da Inovação: Interação Universidade-Empresa no Brasil. Belo Horizonte: Autêntica Editora, (Coleção Economia Política e Sociedade, 3), p.3-16, 2011.

TOPUNIVERSITIES. QS World University Rankings ${ }^{\circledR}$ 2015. 2017. Disponível em: https://www.topuniversities.com/university-rankings/world-university-rankings/2015. Acesso em: 03 abr. 2017. 